\title{
Development of Black Sea nowcasting and forecasting system
}

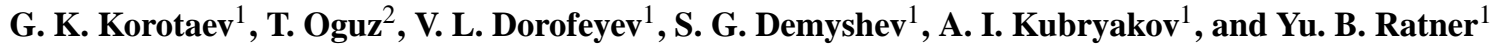 \\ ${ }^{1}$ Marine Hydrophysical Institute National Academy of Sciences, Sevastopol, Ukraine \\ ${ }^{2}$ Institute of Marine Sciences Middle East Technical University, Erdemli, Turkey
}

Received: 1 March 2011 - Published in Ocean Sci. Discuss.: 27 April 2011

Revised: 9 September 2011 - Accepted: 15 September 2011 - Published: 11 October 2011

\begin{abstract}
The paper presents the development of the Black Sea community nowcasting and forecasting system under the Black Sea GOOS initiative and the EU framework projects ARENA, ASCABOS and ECOOP. One of the objectives of the Black Sea Global Ocean Observing System project is a promotion of the nowcasting and forecasting system of the Black Sea, in order to implement the operational oceanography in the Black Sea region. The first phase in the realization of this goal was the development of the pilot nowcasting and forecasting system of the Black Sea circulation in the framework of project ARENA funded by the EU. The ARENA project included the implementation of advanced modeling and data assimilation tools for near real time prediction. Further progress in development of the Black Sea nowcasting and forecasting system was made in the frame of ASCABOS project, which was targeted at strengthening the communication system, ensuring flexible and operative infrastructure for data and information exchange between the Black Sea partners and end-users. The improvement of the system was made in the framework of the ECOOP project. As a result it was transformed into a real-time mode operational nowcasting and forecasting system. The paper provides the general description of the main parts of the system: circulation and ecosystem models, data assimilation approaches, the system architecture as well as their qualitative and quantitative calibrations.
\end{abstract}

\section{Introduction}

The basis for operational oceanography is the observing system providing regular oceanographic data in real time mode. Operational observations together with modern computers,

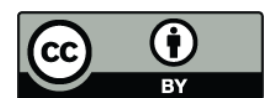

Correspondence to: V. L. Dorofeyev (dorofeyev_viktor@mail.ru) numerical models and data assimilation methods allow developing the marine environment nowcasting and forecasting. Nowcasting and forecasting of marine environment is similar to the meteorological weather prediction. Integrating structurally different sets of observations which are made available by satellite sensors, moorings, floats and ship-based measurements in the marine nowcasting and forecasting systems allows continuous evolution of the ocean fields in a convenient form with rather high accuracy.

The initiatives for setting up a Black Sea marine nowcasting and forecasting system under the umbrella of the European Commission Framework programmes started with the FP5 ARENA project (A Regional Capacity Building and Networking Programme to Upgrade Monitoring and Forecasting Activity in the Black Sea Basin) during the mid2000s. It is further improved in the FP6 ASCABOS project (A Supporting Programme for Capacity Building in the Black Sea Region towards Operational Status of Oceanographic Services) and transformed into a real-time mode operational system in the ECOOP projects (European COastalshelf sea Operational observing and forecasting system) during the second half of the 2000s. The overall goal of ECOOP was to consolidate, integrate and further develop existing European coastal and regional seas operational observing and forecasting systems into an integrated pan-European system. Different basin-scale models mainly resulted from MERSEA system provided initial and boundary conditions for the coastal forecasting. The Black Sea community nowcasting and forecasting system was essential part of the ECOOP. The development and operation system involved a partnership and collaborative efforts of various institutions from the Black Sea riparian states as they joined together in different groups for modelling, observations, data assimilation, data management and serving with limited financial resources. The present form of the Black Sea nowcasting and forecasting system offers a suite of interdisciplinary models and data assimilation schemes that are linked to regional atmospheric

Published by Copernicus Publications on behalf of the European Geosciences Union. 
model products, and observational sensors mounted on a variety of platforms.

A critical element of this remarkable achievement in a rather short time was a long history of scientific collaboration on the Black Sea oceanographic research. The circulation and ecosystem models were run simultaneously at Marine Hydrophysical Institute (MHI), Ukraine and Institute of Marine Sciences (IMS), Turkey. MHI was also responsible for retrieving satellite data, their processing and assimilation into the models. The meteorological data were provided by the high resolution regional atmospheric model which is fully operational at National Meteorological Administration (NMA) in Romania as a regional implementation of the French global atmospheric model ALADIN. The input data to the oceanic models are collected through Internet or downloaded from the data base management system. The model products were also stored by the data base management system at IMS. A back up system exists in NIMRD (Romania) which was also responsible to disseminate the forecast products and analyses data to the institutions such as Institute of Oceanology, Bulgarian Academy of Sciences (IO-BAS), Bulgaria, IGF (Georgia), NMA (Romania), Shirshov Institute of Oceanology (SOI), Russia and MHI (Ukraine) to run their high-resolution sub-regional models.

The presented paper consists of the next main parts: description of the Black Sea circulation models used in the nowcasting and forecasting system with schemes of data assimilation; the circulation model calibration; description and calibration of the biogeochemical model; and architecture of the Black Sea nowcasting and forecasting system.

\section{Black Sea circulation models and data assimilation approach}

Achievements of the operational oceanography during the last decade are considerably connected with significant improvement of the ocean models skill, assimilation procedures (Agoshkov et al., 2010) and increase of computers power. Numerical models of the oceanic circulation and ecosystems (Zalesny et al., 2008; Zalesny and Tamsalu, 2009) can be operated now even on personal computers reproducing rather accurately the state of the marine environment and future changes according to the external forcing.

\subsection{Description of the circulation models}

The Black Sea general circulation models used by the nowcasting and forecasting system are based on the finitedifference approximation of the primitive equations. One of the models is developed by MHI and it is written in the Cartesian coordinate system. The model uses z-coordinate in the vertical direction. It uses Philander - Pacanovsky (Pacanovsky and Philander, 1981) parameterisation of the vertical turbulent viscosity and diffusion. Another model is the implementation of the Princeton Ocean Model (POM), that is also expressed in the Cartesian coordinates in the horizontal directions and terrain following sigma coordinate in the vertical. The Princeton University model has an advantage with respect to the former one in terms of its more sophisticated parameterization of the turbulent viscosity and diffusion using the Mellor-Yamada 2.5 level turbulence closure (Mellor and Yamada, 1982) that permits a more realistic representation of the surface mixed layer and the sub-surface cold intermediate layer. The horizontal currents, vertical velocity, temperature, salinity and turbulent diffusion coefficients obtained by the POM are used to run the ecosystem model in an offline mode.

Both the MHI model and POM equations are discretized on the C-grid (Arakawa, 1966). The momentum equations in the MHI model are presented in Lamb form which conserves energy and potential enstrophy in the barotropic divergencefree case (Demyshev et al., 1992). The MHI model has 35 non-uniformly spaced levels which are compressed towards the free surface and the bottom. Horizontal grid resolution is $5 \mathrm{~km}$ in both directions that resolves well the mesoscale processes with the Rossby radius of deformation of about 20-25 km in deep part of the Black Sea (Dorofeyev et al., 2001). Leap-frog scheme is used for time discretization with periodical switch on of the Matsuno scheme to avoid time slipping feature of the Leapfrog scheme. Vertical coefficients of turbulent viscosity and diffusion were parameterised by Philander-Pakanovsky formula as it was suggested by Friedrich and Stànev (Friedrich and Stànev, 1988). Horizontal turbulent viscosity coefficient and diffusion coefficient were chosen constant and equal to $5 \times 10^{7}$ and $5 \times 10^{5} \mathrm{~cm}^{2} \mathrm{~s}^{-1}$ respectively.

POM has $7 \mathrm{~km}$ horizontal grid step and 26 sigma-levels, which are more frequently near the sea surface and near the bottom. An advantage of the POM model consists of more sophisticated parameterization of the vertical turbulent diffusion and viscosity coefficients. Therefore the results, obtained with the POM model, were used as input parameters for the Black Sea ecosystem model.

The surface and lateral boundary conditions of the models are provided by the regional atmospheric model, and the climatic data for the river runoffs, water and salt transports through the Kerch and Bosphorus Straits. Surface forcing is an output of the ALADIN atmospheric model of National Meteorological Administration of Romania. ALADIN atmospheric model, the limited area version of the global spectral model ARPEGE/IFS of MeteoFrance, is a tool for the dynamical adaptation and simulation of hydrostatic meso-scale phenomena. It has horizontal space resolution of $24 \mathrm{~km}$ and provides $54 \mathrm{~h}$ forecast for the Black Sea of wind stress, evaporation and precipitation, sensitive and latent heat flux, long and short wave radiation every $6 \mathrm{~h}$. Because the Black Sea is a semi-enclosed basin, the lateral boundary conditions are no-slip and zero heat and salt fluxes everywhere except the Bosphorus and Kerch Straits and some major rivers where 
the temperature and salinity boundary conditions are specific at inflow conditions. Diffusive heat and salt fluxes are set to zero in the straits outflow points.

\subsection{Data assimilation approach}

Data assimilation is a procedure permitting to combine observations with model simulations for adequate simulation of the marine environment real state (Ghil and MalanotteRizzoli, 1991). Operational Black Sea circulation model assimilates real-time satellite altimetry and sea surface temperature.

Sea level anomalies provided by AVISO service were converted into the sea level height (SSH) according to the algorithm described by Korotaev (Korotaev et al., 2001). It is then assimilated into the model using the optimal interpolation approach and permits to correct the simulated fields by observations. The correction is performed at the moment of observations and has the following form:

$\widehat{S}(x, y, z, t)=S(x, y, z, t)+\sum_{n=1}^{N} W_{n} \cdot\left[\bar{\zeta}\left(x_{n}, y_{n}, t\right)-\varsigma\left(x_{n}, y_{n}, t\right)\right]$

where $x, y, z$ are spatial coordinates, $t$ is time, $S(x, y, z, t)$ is any field which characterises the sea state (below we shall call it as salinity) and is predicted by the model to the moment of observation, $\varsigma(x, y, z, t)$ is the sea level field which is predicted by the model, $N$ is the number of observations of a field $\zeta$ and $\bar{\zeta}(x, y, z, t)$ is its observed value. $\widehat{S}(x, y, z, t)$ is the optimal estimation of the field $S(x, y, z, t)$ that takes into account observations of the field $\varsigma(x, y, z, t)$. Weight coefficients $W_{n}$ are calculated through the cross-covariance function $P^{S_{\varsigma}}$ of errors of salinity $S$ and sea level $\varsigma$ forecast and the auto-covariance function $P^{\varsigma \varsigma}$ of errors of the field $\varsigma$ (Knysh et al., 1996).

Let us present error covariance functions in the form

$P^{S_{5}}\left(x, y, z, x^{\prime}, y^{\prime}, t\right)=\sigma^{S}(x, y, z, t) \cdot \sigma^{\varsigma}\left(x^{\prime}, y^{\prime}, t\right) \cdot \bar{P}^{S_{5}}\left(x, y, z, x^{\prime}, y^{\prime}, t\right)$

$P^{\varsigma \varsigma}\left(x, y, x^{\prime}, y^{\prime}, t\right)=\sigma^{\varsigma}(x, y, t) \cdot \sigma^{\varsigma}\left(x^{\prime}, y^{\prime}, t\right) \cdot \bar{P} \varsigma \varsigma\left(x, y, x^{\prime}, y^{\prime}, t\right)$

where $\sigma^{S}(x, y, t)$ and $\sigma^{5}(x, y, t)$ are standard deviations of errors of salinity and sea level predictions, respectively, $\bar{P}^{S \varsigma}$ is the cross-correlation function of errors of the sea level and salinity fields and $\bar{P}^{\varsigma \varsigma}$ is auto-correlation function of errors of the sea level. Let the following assumptions:

1. Errors of the predicted fields are stationary in time as well as horizontally uniform and isotropic. Then

$$
\begin{aligned}
& \sigma^{S}=\sigma^{S}(z) \\
& \sigma^{\varsigma}=\mathrm{const} \\
& \bar{P}^{S \varsigma}=\bar{P}^{S \varsigma}(r, z) \\
& \bar{P}^{\varsigma \varsigma}=\bar{P}^{\varsigma \varsigma}(r)
\end{aligned}
$$

where $r^{2}=\left(x-x^{\prime}\right)^{2}+\left(y-y^{\prime}\right)^{2}$.

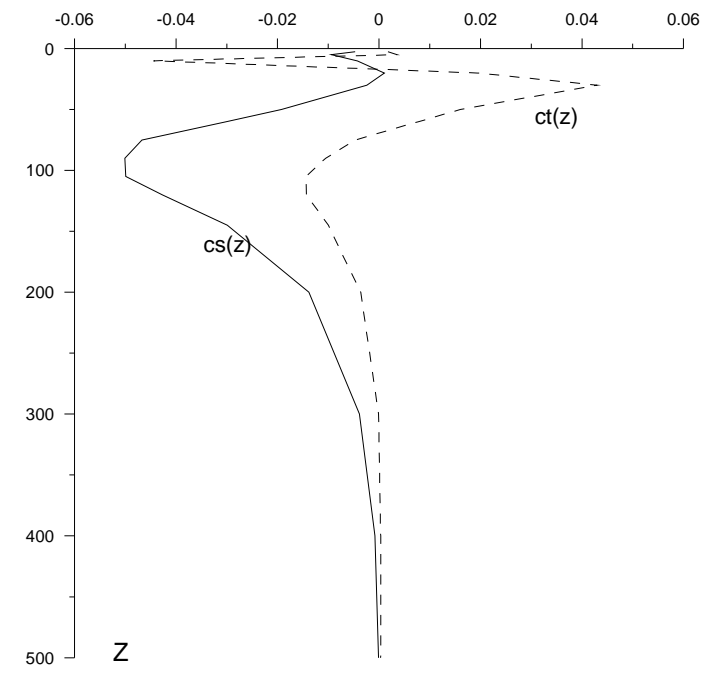

Fig. 1. Normalized weight coefficients for extrapolation of temperature and salinity with depth.

2. Cross-correlation between salinity and sea level is presented as a product of two factors:

$$
\bar{P}^{S_{\varsigma}}(r, z)=\bar{P}^{S_{\zeta}}(r) \cdot \bar{P}^{S_{\varsigma}}(z)
$$

3. A statistic of errors of the predicted fields is proportional to the natural statistics of the same fields.

Under these assumptions, the variance, auto-correlation and cross- correlation functions estimated from observations are used in the simulations. Normalized weight coefficients for the temperature and salinity fields are presented on Fig. 1.

Sea surface temperature (SST) retrieved from NOAA AVHRR data was assimilated in the model. Reception and pre-processing of AVHRR data was carried out by MHI group. SST retrieved from AVHRR measurements on $1 \mathrm{~km}$ grid was interpolated then on the model grid. The assimilation of SST derived from AVHRR sensors was carried out by replacing the simulated temperature within the upper mixed layer by the observed SST. The mixed layer depth was determined by combining the simulated temperature and salinity profiles analysis and Obukhov's formula (Obukhov, 1946), which follows from the turbulent energy balance. Bearing in mind that the cloudiness is impenetrable for IR radiation and some gaps can appear on SST maps derived from AVHRR data. Therefore, the observed SST is optimally interpolated using the SST prediction as a base. Then interpolated values are assimilated as it was explained above. Such approach permits to avoid artificial fronts on the simulated SST maps.

SST and SSH assimilation permits to keep the surface layer thermodynamics and topography of permanent pycnocline close enough to the real state. However operational 
observations in the Black Sea do not cover the deep layers of the basin with required density. Profiling floats observations are too rare and only special approach elaborated last time (Demyshev et al., 2010) should permit to assimilate them. Therefore the stratification of the basin is simulated by the model. The model is not perfect and after long enough integration it slides to its own climate. Typical trends are about 0.05 degrees per year and $0.1 \mathrm{ppt}$ per year in the permanent pycnocline. The model trends are not important for a short term forecast but it should be corrected when the model run is long enough. In our case we have initialized the model stratification in January 2005 and then it is simulated by model more than five years until the end of ECOOP and further in the framework of My Ocean project. Assimilation of the temperature and salinity profiles obtained by averaging of the climatic arrays over the basin area was used in the model which operated during ECOOP to avoid undesirable trends. This method has significant drawback as the climatic profiles are unable to trace decadal variability of vertical stratification. Nevertheless assimilation of the climatic profiles make possible to prevent slow sliding of the model to its own climate.

\section{Circulation model calibration}

The circulation models have been subject to extensive set of qualitative and quantitative tests prior to the operational phase. Next two subsections present some of those tests to show the model ability to reproduce major characteristics of the Black Sea dynamics and important features of the temperature and salinity stratification.

\subsection{Qualitative model calibration}

The Black Sea is an elongated basin situated between $40^{\circ} 56^{\prime}$ and $46^{\circ} 33^{\prime} \mathrm{N}$ with the maximum dimension along the longitude equal to $1148 \mathrm{~km}$. The southern end of the Crimea peninsula and the north point of the Anatolian coast convexity determine the narrowest place of the Black Sea with the width about $260 \mathrm{~km}$ dividing the whole basin on eastern and western sub-basins. The Black Sea is deep enough. Its mean depth is about $1300 \mathrm{~m}$ and its maximal depth is more than $2200 \mathrm{~m}$. A broad shelf with the depth of $0-100 \mathrm{~m}$ occupies the northwestern part of the sea where concentrated $80 \%$ of the river fresh water discharge. All precipitation and half of river fresh water inflow are evaporated. The rest part of the Black Sea water outflows through the Bosphorus Strait. Water exchange through the Bosphorus Strait has a two-layer structure. The Marmara Sea water of higher salinity is transported to the Black Sea along the bottom of the strait. Volume transport of the upper flow (near $0.02 \mathrm{~Sv}$ ) exceeds twice the lower one. Correspondingly, the salinity of the Marmara Sea is approximately twice higher than that on the surface of the Black Sea. Inflow of the salt water through the Bospho- rus Strait determines the density stratification of the sea. The deep-sea salinity is near $22.5 \mathrm{ppt}$ against $18-18.5 \mathrm{ppt}$ on the surface. A well-pronounced permanent pycnocline is situated on the depth of 150-300 m that makes internal Rossby radius be equal to $25 \mathrm{~km}$.

Monthly-mean atmospheric circulation is of a cyclonic character above the Black Sea during the whole year. Prevailing of cyclones provides positive wind stress curl for the whole year with maximum in winter and minimum in summer. The positive wind stress curl and the buoyancy contrast between the fresh river inflow and salt water supply through the Bosphorus Strait induce cyclonic circulation in the sea. A permanent feature of the upper layer circulation is the Rim Current, encircling the entire Black Sea and forming a largescale cyclonic gyre. The Rim Current is located above the continental slope and has the width of $40-80 \mathrm{~km}$. Direct observations of current velocity from surface buoys show that the maximum speed of the stream is usually $40-50 \mathrm{~cm} \mathrm{~s}^{-1}$ increasing sometimes up to $80-100 \mathrm{~cm} \mathrm{~s}^{-1}$. The shape of the coastline probably conditions appearance of two smaller cyclonic gyres in the western and the eastern parts of the basin.

The Rim Current is concentrated above the shallow pycnocline and the volume transport by the current is estimated as 3-4 Sv. A general opinion is that shallow and sharp pycnocline restricts propagation of seasonal signal from the surface and seasonal variability is concentrated in the upper $100 \mathrm{~m}$. General cyclonic circulation induces the rise of the dynamical sea level toward the coast. Full range of spatial variability of the dynamical sea level depends on a season and changes from 25 to $40 \mathrm{~cm}$ so that the mean amplitude of the sea level spatial variability is about $15 \mathrm{~cm}$ (Blatov et al., 1984).

Large-scale hydrographic surveys, satellite observations and eddy-resolving numerical simulations show that the instantaneous surface currents differ from a simple gyre due to the strong mesoscale variability (Sur et all., 1994; Kortaev et al., 2003). Permanent and transient mesoscale anticyclones are observed at the right side from the jet. The most prominent feature is the anticyclonic eddy in the southeastern corner of the basin. Strong meanders of the Rim Current and mesoscale eddies are formed near the Bosporus Strait and along the Anatolian coast. The area of the bottom slope between the northwestern shelf and the deep part of the sea is also the region of the increased mesoscale variability resulted from the Rim Current meandering. The internal Rossby radius, which is equal to $25 \mathrm{~km}$, defines a typical length scale of mesoscale features. The mesoscale variability of the sea level may have the amplitude of $10-15 \mathrm{~cm}$ as the velocity of surface mesoscale currents achieves $50 \mathrm{~cm} \mathrm{~s}^{-1}$.

Surface geostrophic currents derived from altimetry (Korotaev et al., 2001) manifest obviously annual cycle of the basin circulation. The Rim Current is the most intense in winter-spring seasons. Summer circulation attenuates significantly and in the autumn season the Rim Current usually brakes on the set of mesoscale eddies. Simple explanation of the Black Sea seasonal cycle of circulation is done 

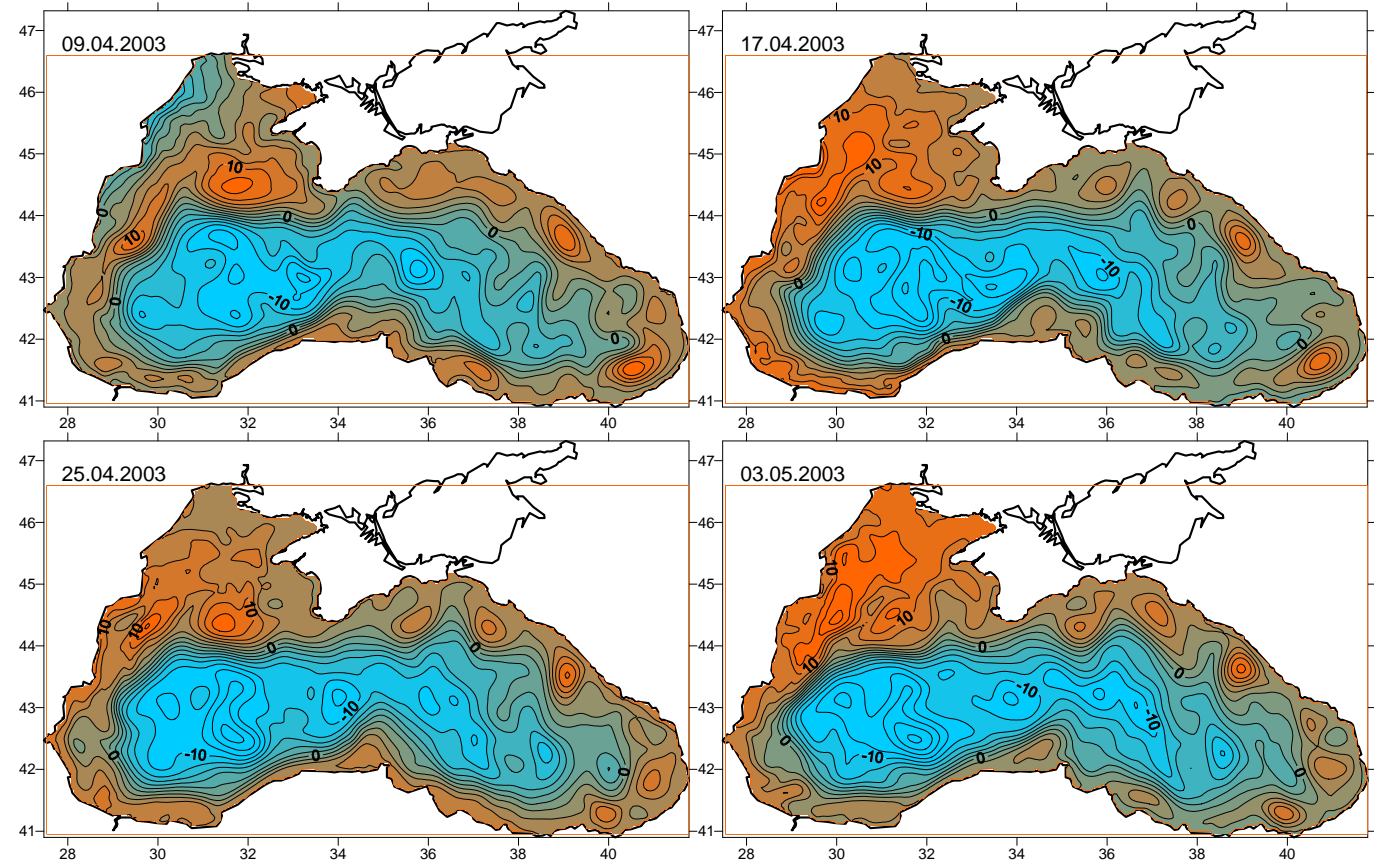

Fig. 2. Short-term evolution of the sea surface topography.

by (Korotaev et al., 2001, 2003). Increase of the cyclonic vorticity of the surface wind in January produces intensification of the upwelling on the bottom of Ekman layer, which induces the rise of pycnocline. The shallowest pycnocline observes a quarter of period (i.e. three months) later. However, the rise of pycnolcline in the central part of the basin should be compensated by its deepening near the coast due to the conservation of the fluid volume. The deepening of pycnocline occurs above the continental slope where the onshore velocity component breaks the geostrophyc balance. The displacement of the pycnocline near the coast is significantly higher than its rise in the open sea as the volume of fluid replaced in the center of the basin should be preserved along the beach. Therefore, the slope of pycnocline toward the coast increases significantly at the beginning of spring. The intensity of the Rim Current, which is in geostrophic balance, is highest at the same time. The weakening of the wind stress curl in summer vice versa is accompanied by the deepening of pycnocline in the open sea ant its rise near the coast. The reduction of the pycnocline slope is manifested at the attenuation of the Rim Current.

The overall circulation system possesses a set of quasipersistent anticyclonic eddies on the coastal side of the Rim Current zone (Kortaev et al., 2003). The most notable features include the Bosphorus, Batumi, Sukhumi, Caucasus, Kerch, Crimea, Sevastopol, Constantsa, and Kaliakra anticyclones. The Bosphorus eddy is observed on the average for 260 days per year with a mean lifetime of about 85 days. The Batumi anticyclone forms in early March and lives usually until the end of October. An average it is observed during 210 days per year. The Sukhumi eddy is manifested about 120 days per year and exists typically for about a month once it forms. It is mostly observed in autumn-early winter months after the collapse of the Batumi gyre. The Caucasus eddy appears about 160 days per year starting at spring. The Kerch eddy is also one of the most pronounced features of the Black Sea eddy dynamics with an average persistence of 240 days and a mean lifetime of 80 days. The spring and autumn seasons are found to be more favoured periods for its presence. The Crimea anticyclone occurs mainly in August-September, and is observed around 115 days per year. The mean period for each event is about a month. The winter and summer are found to be most preferred periods for formation of the Sevastopol eddy. It is observed for about 150 days per year and has the mean lifetime of 50 days. The Constantsa and Kaliakra anticyclones are observed for about 190 days per year with a typical lifetime of about 50 days.

A chain of eddies is observed also along the Anatolian coast but usually they have more intermittent character and travel slowly eastward along the coast. The Sakarya, Sinop and Kizilirmak eddies tend to exhibit more quasi-permanent character due to controls exerted by regional topographies.

The Black Sea circulation model was first calibrated by the climatological data. The attention was focused particularly on reproduction of the Black Sea Rim Current and its seasonal variability as well as main coastal anticyclonic eddies (e.g. Batumi gyre). Other specific features for the model calibration are the reproduction of the main halocline, the 


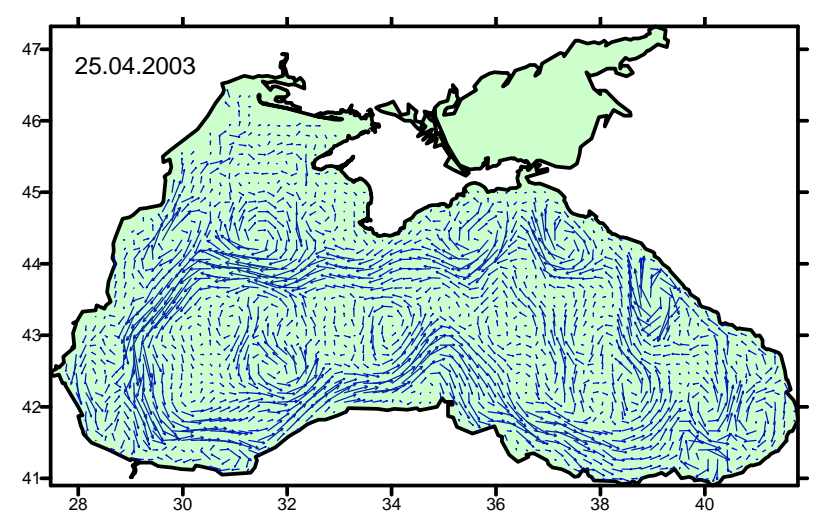

Fig. 3. Surface circulation in spring season simulated by the model.

seasonal thermocline, salinity decrease from the basin center to its periphery. It is necessary to evaluate the model possibility to reproduce the cold intermediate layer (CIL), its reproduction sites and two mechanisms of formation (e.g. winter convection in the central part of the basin and subduction of cold waters from the northwestern shelf).

An example of the Black Sea surface topography evolution during April 2003 is shown on Fig. 2. The strong gradient around the periphery corresponds to the Rim Current jet, its contours are streamlines of the surface geostrophic currents; thus, closed contours represent mesoscale eddies. The overall circulation system shown in Fig. 2 therefore possesses the meandering Rim Current system cyclonically encircling the basin and a set of coastally-attached anticyclonic eddies around the basin, the most notable of which are the Bosphorus, Batumi, Sukhumi, Caucasus, Kerch, Sevastopol, and Constantsa anticyclonic eddies on the coastal side of the Rim Current zone. The Batumi anticyclone is present in the south-eastern corner of the basin as the most intense and persistent of the Black Sea coastal eddies. The Rim Current structure is shown also on Fig. 3.

The maps of temperature distribution on the $50 \mathrm{~m}$ depth reveal a complex picture of spatial variability caused by shear currents (Fig. 4). For example, Fig. 4a shows relatively warm and salty Mediterranean water injected by the Mediterranean underflow near the northern exit of the Bosphorus Strait and its subsequent distribution by currents. It appears to be an intermittent feature depending on the character of large scale circulation features near the strait. Small lenses of warm water similar to "meddies" in the Atlantic Ocean near the Gibraltar strait are formed near the Bosphorus mouth and then transported by Rim current. Such warm lens is seen in Fig. $4 \mathrm{a}$ in the southeast corner of the basin. Such features have not been documented and yet to be confirmed by observations.

Figure $4 \mathrm{~b}$ shows subduction of cold waters (dark color) from the northwest shelf to the deep sea. In the same figure the set mushroom-like structures also is visible near the

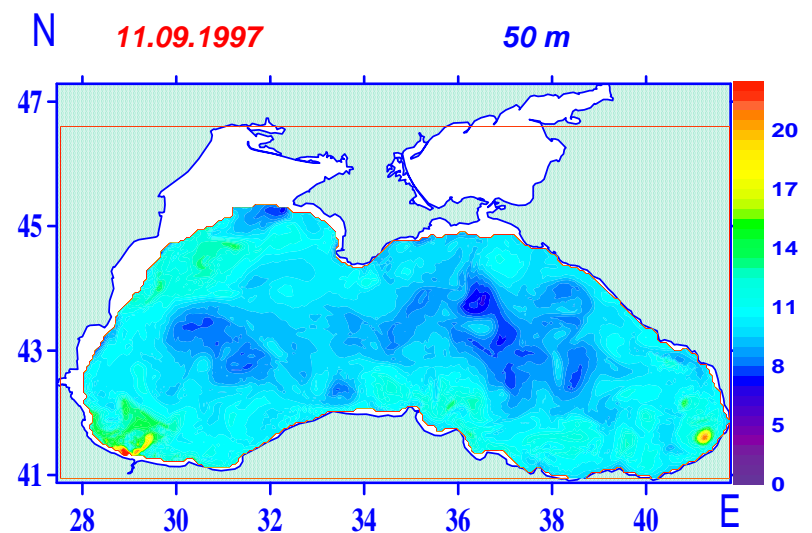

a)

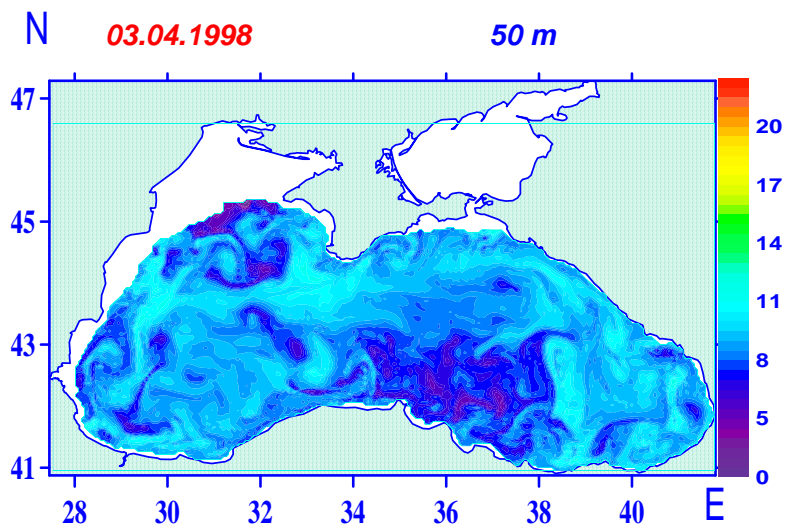

b)

Fig. 4. Temperature distribution on the depth $50 \mathrm{~m}$.

northwest shelf of the sea, in the southwestern corner of basin just opposite to a mouth of the Bosporus Strait and along the Anatolian coast. Usually such mushroom-like structures are observed on the sea surface on satellite images, but rarely captured by direct observations that require high resolution synoptic sampling at the right time and location.

Figure 5 presents distribution of salinity anomalies at $105 \mathrm{~m}$ during September 1995. Light colors correspond to the salinity lower than basin-average value, and vise-versa for dark colors. Eddies of different signs are presented in deep waters according to Fig. 5. Low salinity water is preferentially observed in the coastal anticyclonic eddies, whereas more salty water is observed in cyclonic gyres of the interior basin. As documentred previously (Korotaev et al., 2001, 2003), the Rim current is relatively weak in the summer and fall seasons and the basin acquires more turbulent flow structure of mesoscale eddies as also supported by Fig. 5 .

The vertical section of water temperature along $42.7^{\circ} \mathrm{N}$ is presented on Fig. 6. It illustrates a typical vertical structure of the temperature in the Black Sea. The mixed layer occupies the upper $25 \mathrm{~m}$. The water temperature decreases below the 
$\mathrm{N}$

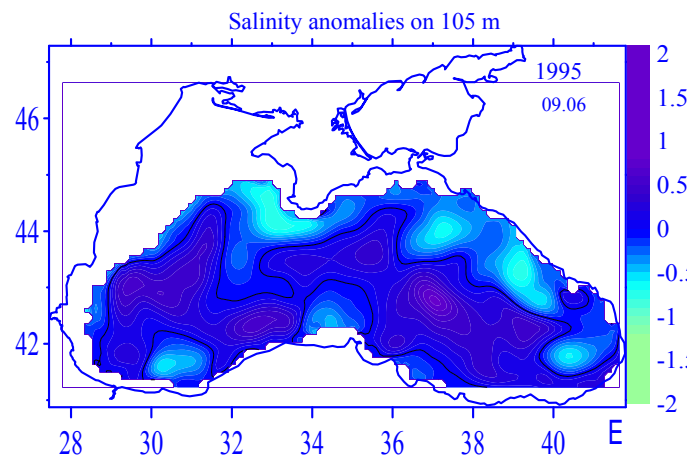

Fig. 5. Salinity anomaly on the depth $105 \mathrm{~m}$.

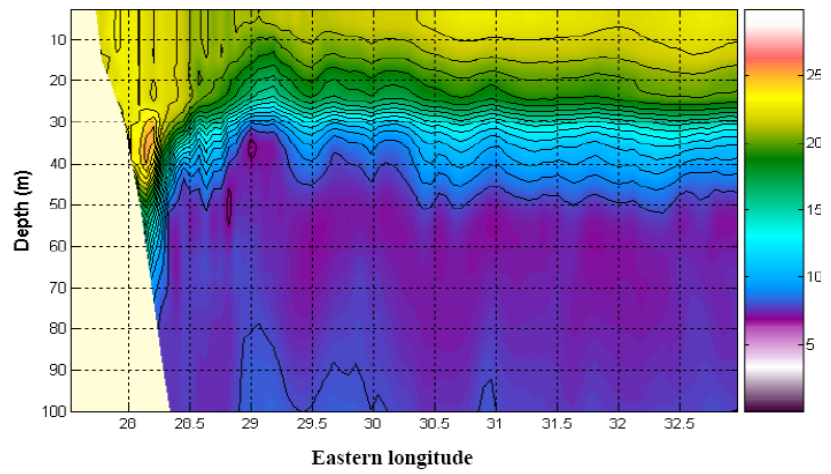

Fig. 6. Temperature section along $42.7^{\circ} \mathrm{N}$ in the upper $100 \mathrm{~m}$ on 29 September 2005. Contour interval is equal to $1^{\circ} \mathrm{C}$. The lowest and the next isotherms correspond to $8^{\circ} \mathrm{C}$ and bound the CIL section.

upper mixed layer forming a seasonal thermocline. The cold intermediate layer (CIL), which is a specific feature of the Black Seas thermal stratification, occupies the layer between 50 and $80 \mathrm{~m}$ depth (violet colour on Fig. 6). The temperature grows below the CIL down to the bottom.

The Rim current frontal zone can be clearly seen in the left part of the section. The deepening of the thermocline as well as the Rim current jet is attached to the bottom slope. General features of the basin dynamics and stratification are well presented by model results.

\subsection{Quantitative model calibration}

Quantitative calibration of the simulated fields is an essential part of the Black Sea forecasting system development. This calibration is carried out with use of regular space remote sensing measurements, in situ data of hydrographic surveys, surface drifting buoys and deep profiling floats.
$\mathrm{N}$

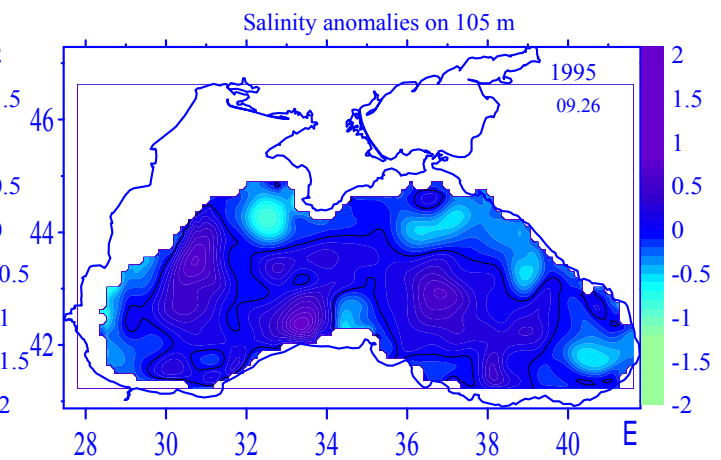



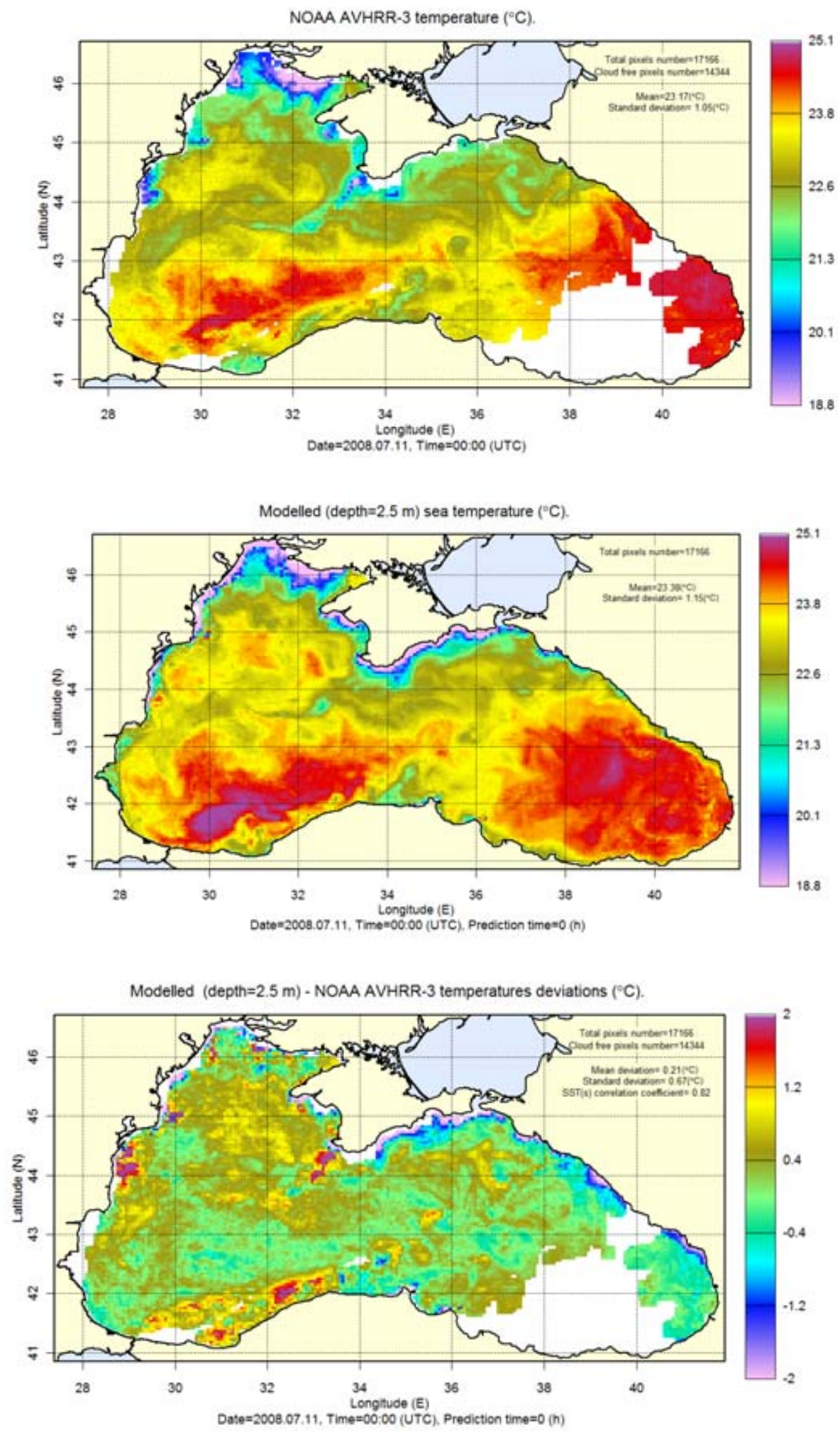

Fig. 8. SST maps on 11 July 2008 retrieved from AVHRR data (upper panel), simulated by the model (central panel) and their difference (lower panel). 
and salinity field simulations. Standard deviations of simulated fields against the observed ones were calculated on each depth level (Dorofeyev and Korotaev, 2004a). These functions are presented on Fig. 7. The standard deviation of the model analysis is compared with the natural variability of the temperature and salinity fields, i.e. with the standard deviation of the climatic data against observations.

Figure 7 shows, that the altimetry assimilation brings the most significant improvement in salinity field. It is natural, because density stratification in the Black Sea depends mainly on salinity. Assimilation of altimetry allows describing about $25 \%$ of the salinity natural variability within the halocline where the difference between simulated and measured fields is the most significant. In the regions of high vertical gradients even small error in the isohaline depth produces large error. However simulated salinity maps agree well with observations, as it was shown earlier by (Dorofeyev and Korotaev, 2004a).

Standard deviation of temperature is the largest near the surface (here the error is greater than in the case of comparison with buoy data). It means that the thermodynamics of the top sea layer in the model is too simplified. An explicit description of the mixed layer dynamics is necessary to include for better reproduction of surface temperature by the model. Additional extremes of the temperature standard deviation are observed near the thermocline and within CIL. Increase of the error near the thermocline has the same reason, as in the case of salinity.

The correlation coefficients of simulated and observed fields of temperature and salinity are large enough. The highest correlation for both fields occurs within the pycnocline with approximately 0.65 for salinity and 0.45 for temperature.

The comparison of the model output with ComsBlack hydrography has shown reasonable consistency of the simulations against observations in deep layers of the basin and further points to the importance of SST assimilation.

\subsubsection{SST calibration}

Calibration of SST was one of the major issues of the ECOOP project as the space SST observations were available in all basins where coastal forecasting activity was carried out. Development of common SST validation standards, which provide a basis for model confidence diagnosis, definition of a quality controlled validation database structure from distributed data centres and common protocol to calculate standard validation criteria was realized at the design of online model validation system to provide NRT model confidence. An experience of MERSEA, MFSTEP, ODON projects and other ongoing operational forecasting activity was taken into account for the selection of important characteristics and proper protocols.

On-line validation of SST analysis and three days forecast was carried out by the coastal forecasting systems and dis- played on the ECOOP site. However SST maps produced by the basin-scale systems which provided boundary conditions for the coastal prediction, particularly the Black Sea basinscale nowcasting/forecasting system, were calibrated off-line to achieve reasonable accuracy.

Data of IR scanner AVHRR are available in the Black Sea region through the direct reception on HRPT receiving stations in Marine Hydrophysical Institute (MHI) in Sevastopol, Ukraine. Up to four IR images of the Black Sea surface are available daily. MHI processes this data regularly in the real time retrieving and mapping the Black Sea surface temperature. Standard NOAA algorithm is used for the retrieving of SST but the threshold for the filtration of cloudiness is adjusted to the Black Sea conditions. Ground truth validation of IR SST against surface drifting buoys data shows its rms accuracy around $0.5-0.7^{\circ}$ (Ratner and Bayankina, 2004). SST maps retrieved from NOAA satellite observations are used to calibrate basin-scale circulation model.

Figure 8 presents typical example of SST maps retrieved from AVHRR data, analysis simulated by the model and their difference. The bias of two maps is equal $0.21{ }^{\circ} \mathrm{C}$, standard deviation is equal $0.67^{\circ} \mathrm{C}$ and correlation coefficient is equal 0.82 . Statistics was simulated by averaging over the cloud free are of the Black Sea basin. At the same time the lower panel on the Fig. 8 shows that the difference between measured and simulated SST in the most part of the basin area is in the range $\pm 0.5^{\circ} \mathrm{C}$. More significant difference observes in the vicinity of frontal zones where model provides higher temperature.

Temporal evolution of the statistics is shown on Fig. 9. Mainly the statistics is similar to that presented on Fig. 8. However, sharp changes of the bias are observed on Fig. 9. Probably they are related with inconsistency of the space SST, as the model provides smooth evolution of simulated fields.

The daily averaged simulations of SST by the basinscale model were compared also with similar data of surface drifters. It is shown (Ratner and Bayankina, 2004) that the standard deviation is in the range $0.5-0.7^{\circ} \mathrm{C}$ (i.e. it is in the same range as the accuracy of SST retrieving from AVHRR data). Accuracy of SST forecast is reduced with the time of prediction. Typically bias lies in the range $\pm 0.4{ }^{\circ} \mathrm{C}$ on the three day forecast. Standard deviation increases up to $0.9^{\circ} \mathrm{C}$ for one day forecast, up to $1.1^{\circ} \mathrm{C}$ for two days forecast and up to $1.2^{\circ} \mathrm{C}$ for three days forecast. Correlation coefficient decreases approximately linearly with the prediction time up to reducing on $10 \%$ to the third day.

\subsubsection{Drifters with thermistor chain}

Drifters with thermistor chain were elaborated under the support of Science and Technical Center in Ukraine (project $\mathrm{N}$ 2241) to be able calibrate upper layer thermodynamics of the Black Sea circulation model. Drifting buoys with thermistor chain provide direct measurements temperature profiles 


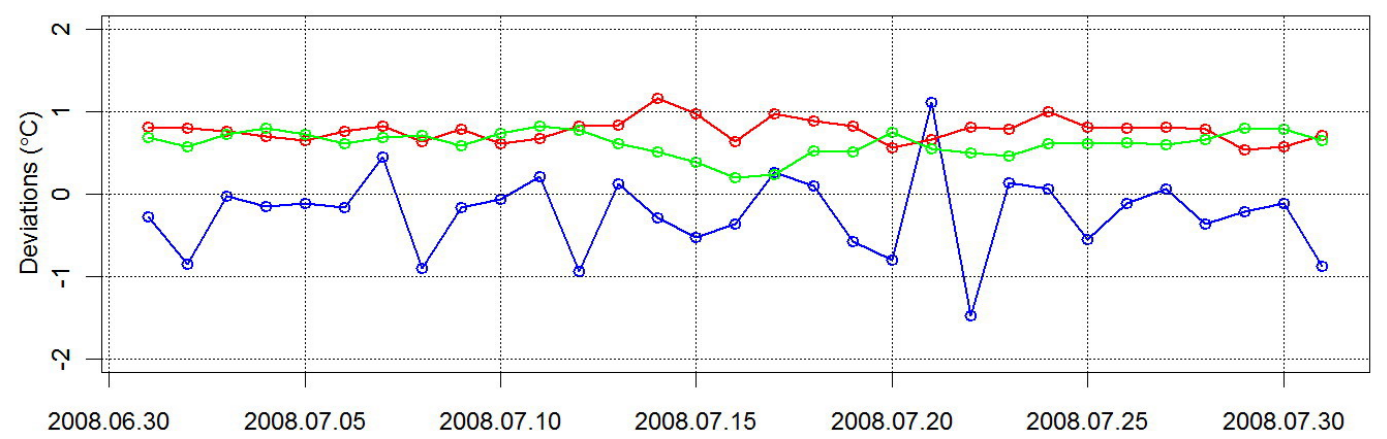

Fig. 9. Bias (blue line), standard deviation (red line) and correlation coefficient between SST retrieved from AVHRR data and simulated by the model as function of time.
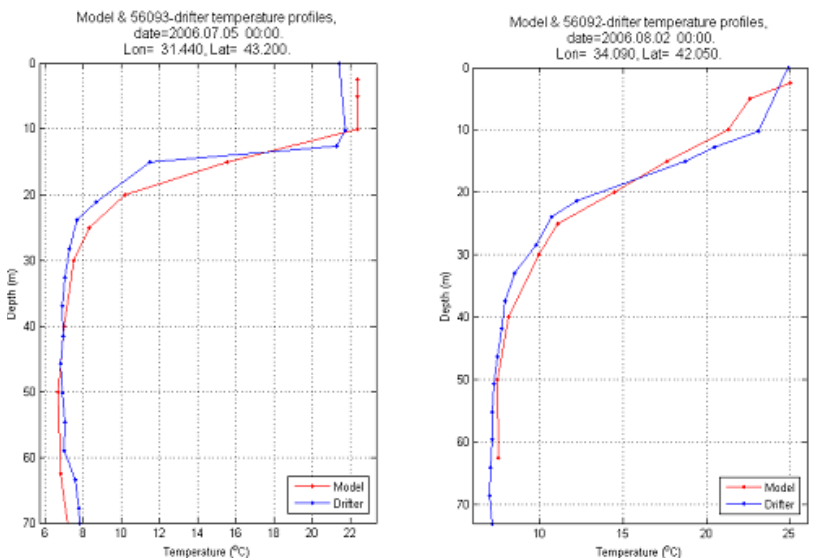

Fig. 10. Comparison of the simulated (blue line) and measured (red line) temperature profiles in the upper $70 \mathrm{~m}$ during the shoaling of the mixed layer.
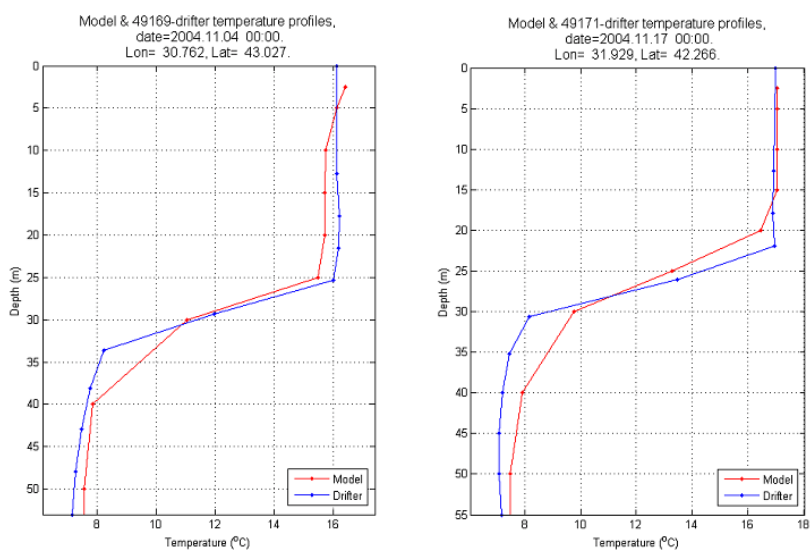

Fig. 11. Comparison of the simulated (blue line) and measured (red line) temperature profiles in the upper $70 \mathrm{~m}$ during the deepening of the mixed layer.
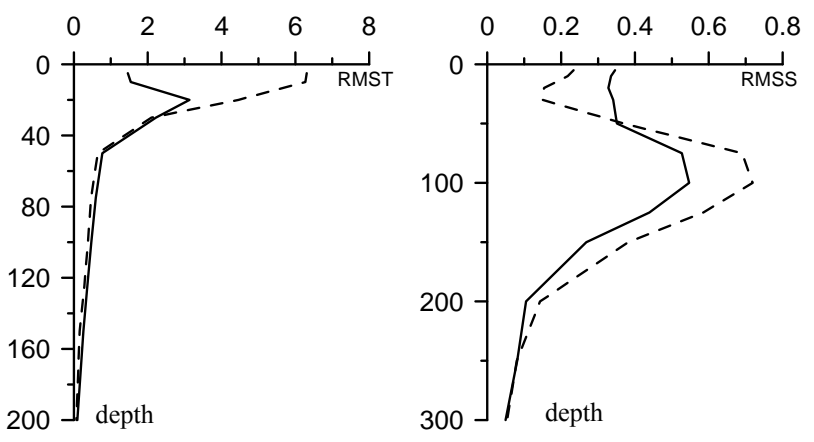

Fig. 12. Standard deviation of the differences between simulated and measured fields as a function of depth (solid lines), and the natural variability of the same fields (dash lines).

in the upper $70 \mathrm{~m}$ layer of the Black Sea. Both shoaling and deepening of the seasonal thermocline were covered by observations. Quality of the products of the upper layer thermodynamics is improved by comparing the simulated temperature profiles in the upper $70 \mathrm{~m}$ layer with direct measurements by the surface drifting buoys with thermistor chain. Careful tuning of the Phylander-Pakanovsky approximation to the Black Sea conditions was done by Demyshev (Demyshev et al., 2009). Improved version of the circulation model provides reasonable description of both shoaling and deepening of the mixed layer (Figs. 10 and 11).

Typically the standard deviation has a maximum on the seasonal thermocline depth. Such maximum has the following explanation. There is a strong temperature gradient in the seasonal thermocline and even small inconsistency of its positioning by the model is resulted in rather significant deviation of temperature.

\subsubsection{Profiling floats}

Temperature and salinity profiles are also compared with data provided by profiling floats. Figure 12 demonstrates the standard deviations for temperature and salinity fields, which are 

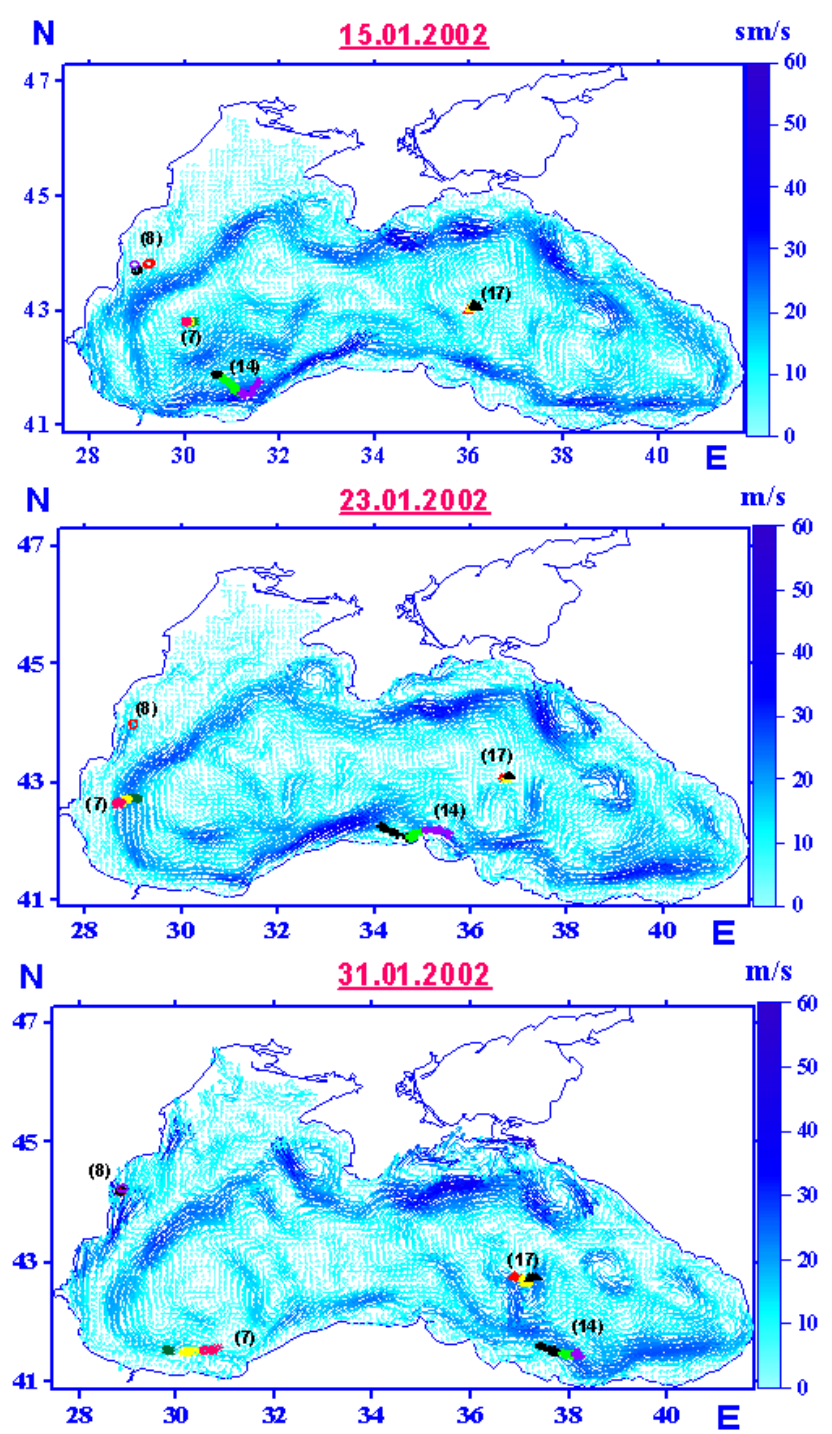

Fig. 13. Trajectories of surface drifting buoys overlapped on the simulated circulation. January 2002.

similar to those obtained by using earlier by the ComsBlack surveys (Dorofeyev and Korotaev, 2004b). The most significant deviation of simulated and measured temperature is observed in the thermocline layer $(10-30 \mathrm{~m})$. Temperature minimum in the cold intermediate layer on in-situ profile is more significant than on temperature profile, simulated by the model. The difference between simulated and observed temperature decrease significantly with depth.

The simulated salinity profiles differ most significantly from mesurements in the layers between $0-30$ and 150$300 \mathrm{~m}$, i.e. in seasonal and permanent pycnocline where it may deviate up to $0.2 \mathrm{ppt}$. The difference between simulations and observations decreases significantly below the permanent pycnocline does not exceeding 0.05 ppt.
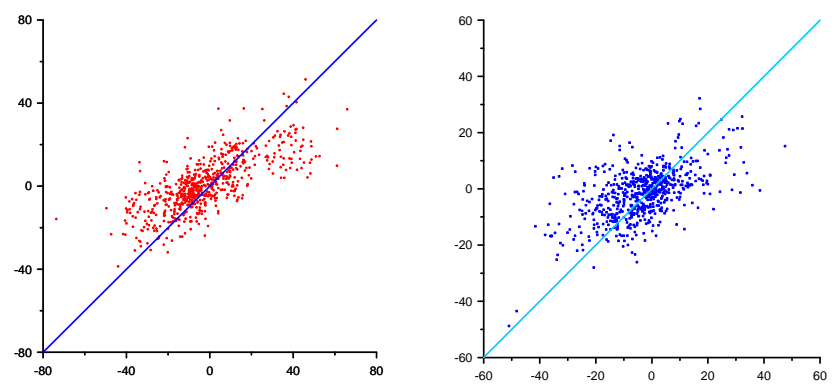

Fig. 14. Scatter plot of the simulated (vertical axe) and observed (horizontal axe) surface currents. Left and right plots correspond to zonal and meridional components of the current velocity respectively.

\subsubsection{Surface velocity}

Comparison of several drifting buoys trajectories with the simulated surface currents in January 2002 is presented in Fig. 13. Trajectories are computed from the buoy coordinates during three days and the simulated currents at middays in the figure. For example, the trajectories of the buoy numbers 7 and 14 were under the influence of Rim Current. Buoy number 14 has been captured by the current for almost a month starting from 15-16 January 2002. We note its circular motion near the cape Sinop as inferred from its trajectories during 23 and 31 January. Buoy number 7 also has been captured by the stream of Rim Current on 23 January. It moved along the offshore side of the jet and has practically left the current on February 2002 and picked up again as they move eastward along the coast of Turkey. The buoy number 17 was located in the open part of the sea during the same period and was transported on the east by mesoscale jets periodically produced as clearly seen on 31 January in Fig. 13.

The trajectory of the buoy number 8 in Fig. 13 illustrates an accuracy of coastal currents simulations. The drift of buoy number 8 during 15-31 January well corresponds to the model simulated narrow coastal jet in the northeast direction in the vicinity of cape Kaliakra of the Bulgarian coast. A small branch of the jet has transported the buoy number 8 towards the shore on 31 January where it remained up to the mid of February 2004. More examples of buoys trajectories are presented in (Korotaev et al., 2004). The evolution of current velocity along the trajectory of drifting buoy also demonstrates good reproduction of the low-frequency flow variability by the model (Korotaev et al., 2004).

The quantitative comparison of the daily averaged surface current velocity and simulations shown on Fig. 14 for zonal and meridional components. The relative error is in the range of $30 \%$, correlation coefficient is equal to 0.7 . Nevertheless, it is seen on Fig. 14 that the simulated velocity components are systematically underestimated by the model. This may be resulted from the different spatial averaging of the 
Model \& 13480-drifter current velocity zonal components. $\mathrm{H}=2.5 \mathrm{~m}$.
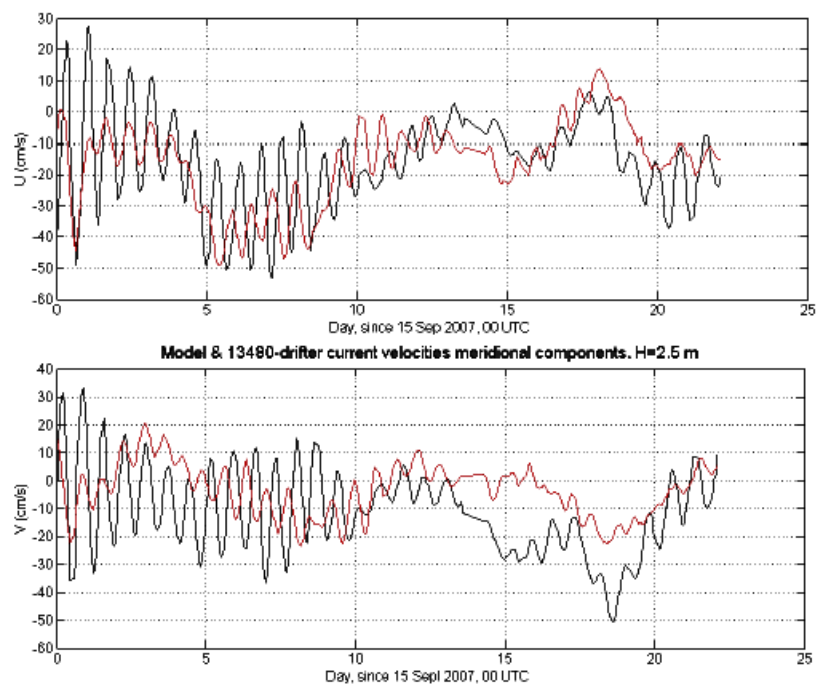

Fig. 15. Comparison of the measured (black) and simulated (red) inertial oscillations.

signal. Drifting buoys measure currents along a line whereas the model simulated velocity is averaged in the box $5 \times 5 \mathrm{~km}$. High resolution surface current maps obtained by means of the imagery processing (Korotaev et al., 2008) show that the Rim current has fine structure in the form of narrow and intense submesoscale jets. However the current grid size of the model $(5 \mathrm{~km})$ is able to resolve mesoscale eddies but not submesoscale structures. Future improvement of the Black Sea operational model should include explicit representation of submesoscale features.

Surface drifting buoys with data transmission via IRIDIUM provide a possibility to validate high-frequency variability of surface currents. IRIDIUM data transmission allows to determine buoy coordinates often enough to describe trajectory loops related to the inertial oscillations. The comparison of measured and simulated current velocity oscillations at inertial frequency (Fig. 15) shows that they can strongly disturb instant surface current velocity. The model often reproduces the phase of inertial oscillations whereas their amplitude usually is underestimated. Evidently, the accuracy of the inertial oscillation simulations depends strongly on the quality of atmospheric forcing.

\subsubsection{Deep velocity}

Data of profiling floats allow evaluation of the weekly averaged deep velocity accuracy. In general, relative accuracy of the current speed simulation by the model is highest on the depth $200 \mathrm{~m}$. However weekly mean currents even on the depth $1550 \mathrm{~m}$ measured by profiling float and simulated by the model are in good consistency (Dorofeyev and Korotaev, 2004b). Relative error is about 30-35\% and correlation coefficient is in the range $0.65-0.72$.

\section{Ecosystem model}

The main part of the Black Sea ecosystem model is a biogeochemical model. The 3D biogeochemical model coupled with the circulation model is based on the one given by Oguz et al. (2001). It has one-way coupling with circulation model through current velocity, temperature, salinity and turbulent diffusivity. The biogeochemical model extends to $200 \mathrm{~m}$ depth with $26 \mathrm{z}$-levels, compressed to the sea surface. It includes 15 state variables. Phytoplankton is represented by two groups, typifying diatoms and flagellates. Zooplankton are also separated into two groups: microzooplankton (nominally $<0.2 \mathrm{~mm}$ ) and mesozooplankton $(0.2-$ $2 \mathrm{~mm}$ ). The carnivorous group covers the jelly-fish Aurelia aurita and the ctenophore Mnemiopsis leidyi. The model food web structure identifies omnivorous dinoflagellate Noctiluca scintillans as an additional independent group. It is a consumer feeding of phytoplankton, bacteria, and microzooplankton, as well as particulated organic matter, and is consumed by mesozooplankton. The trophic structure includes also nonphotosynthetic free living bacteriaplankton, detritus and dissolved organic nitrogen. Nitrogen cycling is resolved into three inorganic forms: nitrate, nitrite and ammonium. Nitrogen is considered as the only limiting nutrients for phytoplankton growth. So all these variables are presented in the model equations in units $\mathrm{mmolN} / \mathrm{m}^{3}$. Additional components of the biogeochemical model are dissolved oxygen and hydrogen sulfide. The local temporal variations of all variables are expressed by equations of the general form

$$
\begin{aligned}
& \frac{\partial F}{\partial t}+\frac{\partial(u F)}{\partial x}+\frac{\partial(v F)}{\partial y}+\frac{\partial\left(\left(w+w_{s}\right) F\right)}{\partial z} \\
& =K_{h} \nabla^{2} F+\frac{\partial}{\partial z}\left(K_{v} \frac{\partial F}{\partial z}\right)+\mathfrak{R}(F),
\end{aligned}
$$

where $\mathfrak{R}(F)$ is the interaction term, which expresses a balance of sources and sinks of each of biological and geochemical variables $F ; w_{S}$ represents the sinking velocity for diatoms and detrital material and is set to zero for other compartments; $(u, v, w)$ - components of the current velocity, $K_{h}, K_{v}$ - horizontal and vertical coefficients of turbulent diffusion. The last parameters are provided by physical model (the circulation model). The biogeochemical model, described here, uses the MHI or POM model output, so its space resolution is equal to the space resolution of appropriate circulation model.

Fluxes of all biogeochemical variables are set to zero on the sea surface, bottom in shallow part of the basin and on the lateral boundaries, except river estuaries, where nitrate fluxes are set up proportional to rivers discharges and nitrate concentrations. On the lower liquid boundary in the deep part of the basin concentrations of all parameters set to zero except ammonium and hydrogen sulfide (sulfide and ammonium pools). 

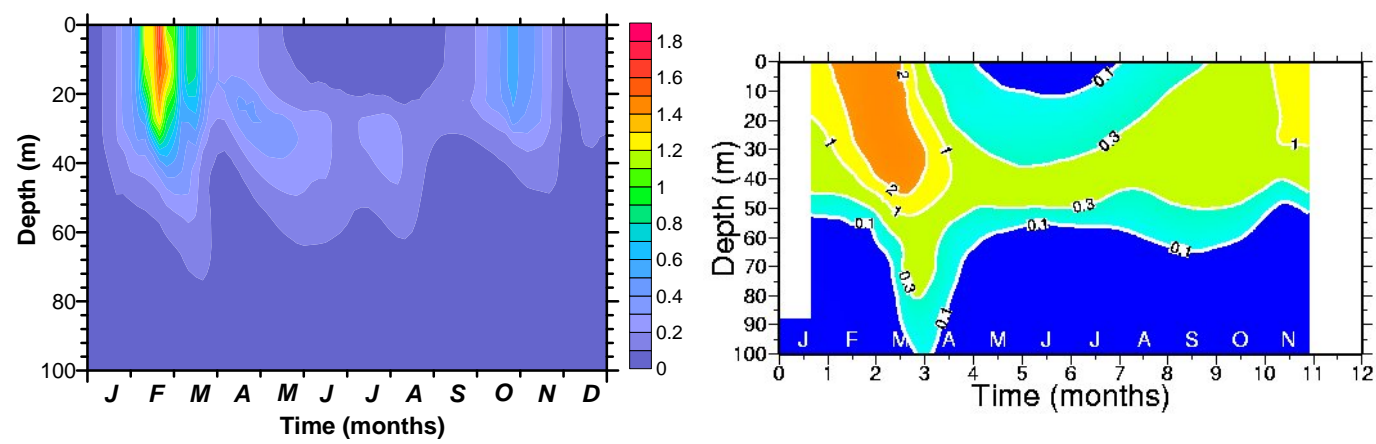

Fig. 16. Seasonal cycle of averaged over the basin area phytoplankton derived from modelling (left panel) and chlorophyll seasonal cycle in the upper layer of the Black Sea on the basis of in-situ measurements (Vedernikov and Demidov, 1997).
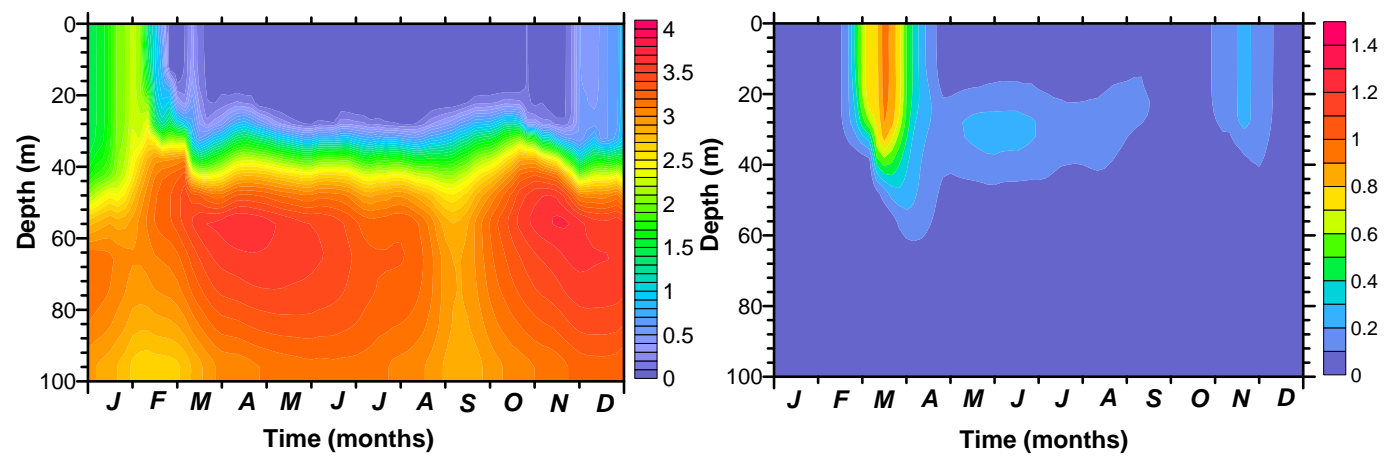

Fig. 17. Seasonal cycles of averaged over the basin area nitrates (left panel) and zooplankton (right panel).

\section{Calibration of the ecosystem model}

Analysis of the model results shows that the model reproduces reasonably well the seasonal cycling of phytoplankton and other biochemical fields. The spring bloom of phytoplankton computed by the model is well presented on the Fig. 14 (left). It shows also the secondary subsurface maximum of phytoplankton on the bottom of the summer and autumn bloom. This seasonal cycle of the phytoplankton in the upper layer of the Black Sea derived from the modeling qualitatively correspond to those obtained from measurements. Figure 16 exhibits on the right panel chlorophyll seasonal cycle in the upper layer of the Black Sea on the basis of in-situ measurements (Vedernikov and Demidov, 1997).

Figure 17 demonstrates seasonal variability of the nitrate and zooplankton concentrations in the upper layer of the Black Sea. Surface concentration of nitrate increases during the winter mixing period and reduces to small value after the spring bloom of phytoplankton. Then it remains negligible until the next winter. The distribution of zooplankton follows closely that of phytoplankton with a time lag of approximately half a month. These seasonal cycles of the phytoplankton, zooplankton and nitrate in the upper layer of the Black Sea derived from the modeling qualitatively cor- respond to those obtained from measurements (Oguz et al., 1999).

An increase of anthropogenic nutrient load together with population explosions in medusa Aurelia during the 1970s and $80 \mathrm{~s}$ led to practically uninterrupted phytoplankton blooms in the Black Sea (Fig. 18). This figure demonstrates intra-annual variability of the phytoplankton, zooplankton biomasses and seasonal cycles of Noctiluca and medusa $\mathrm{Au}$ relia biomasses. The left panel corresponds to the results of the modelling and the right one - to the in-situ measurements (Oguz et al., 2002). The data for phytoplankton and mesozooplankton biomass are taken from measurements carried out at 2-4 weeks intervals during January-December 1978 at a station, off Gelendzhik along the Caucasian coast. The Noctiluca and Aurelia biomass data are taken from measurements on the Romanian shelf and the interior basin, respectively, during the late 1970s and early 1980s (after Oguz et al., 2001). The model data were chosen approximately at same places during 1978 year. The model results are in a good agreement with measurements.

An example of space distribution of the nitrate concentration in the upper $20 \mathrm{~m}$ layer of the Black Sea is presented on the Fig. 19 (left panel). This nitrate concentration is derived by averaging over $4 \mathrm{yr}$ the nitrate fields computed by 


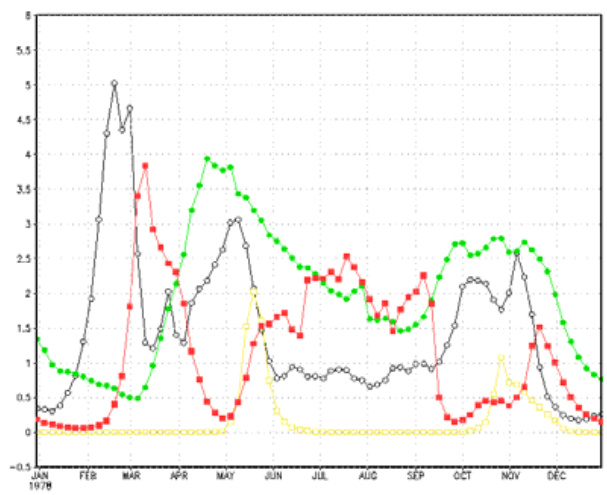

Aurelia-dominated Ecosystem

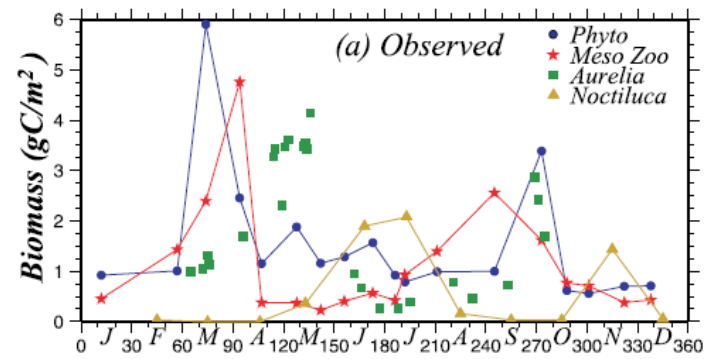

Time (Days)

Fig. 18. Seasonal cycles of phytoplankton, mesozooplankton, Noctiluca and medusa Aurelia biomasses derived from modelling (left) and in-situ measurements.
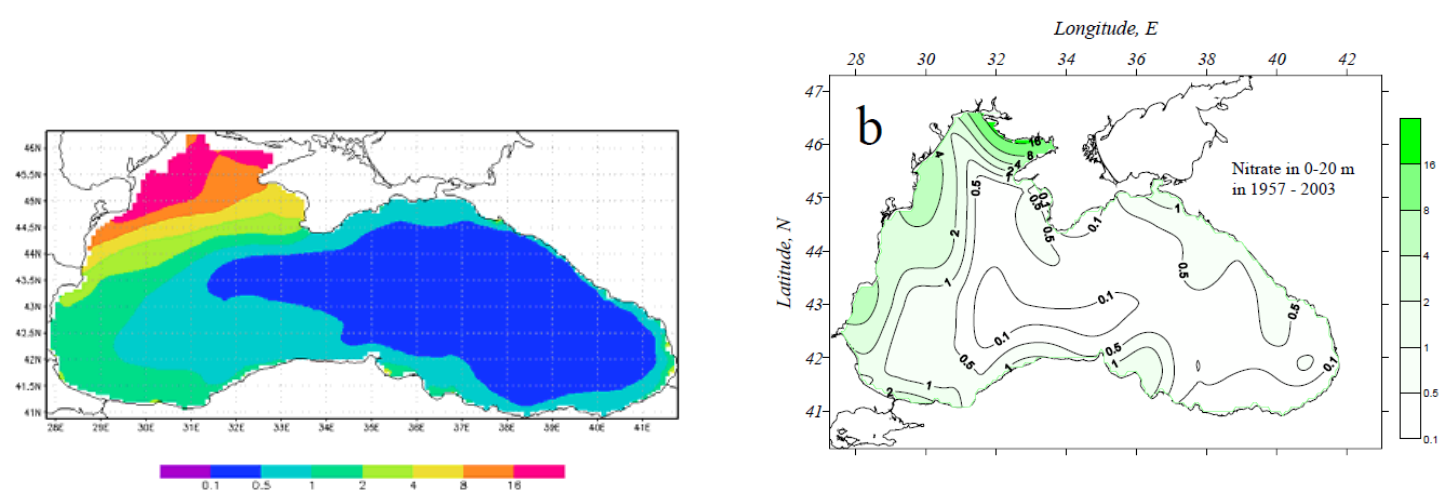

Fig. 19. An example of the surface nitrate space distribution derived from the model (left) and the map built on the basis of in-situ data (fight).

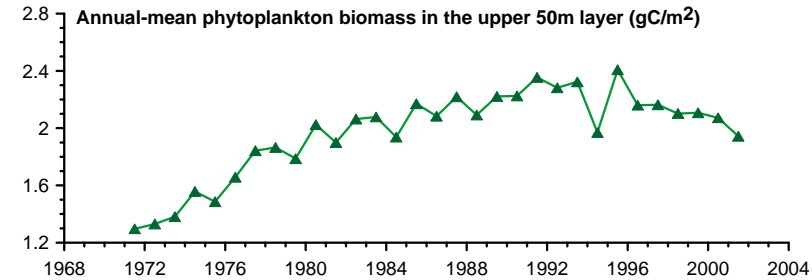

Fig. 20. Evolution of the annual-mean phytoplankton biomass in the upper $50 \mathrm{~m}$ layer for the deep part of the Black Sea basin.

the model. The highest values of nitrate concentration are observed on the northwestern shelf of the Black Sea. It is a response on nitrate supply by Danube and other rivers. High nitrate concentration is observed also along western and south coast due to cyclonic circulation in the Black Sea. The Rim current transports part of the nitrate from northwestern shelf to the Anatolian coast. The right panel of the same Fig. 19 demonstrates mean map of the nitrate distribution in the up- per layer obtained by using in-situ data for the tame period from 1957 until 2003 years (Konovalov and Eremeev, 2011). According to this map the highest concentration of the nitrate in the upper layer are typically for the coastal area on the north-western shelf near the Danube and other rivers and the lowest values can be observed in the central part of the basin. In general there is a good correspondent between these two maps.

An opportunity for qualitative calibration of the model output is given by analysis of long-term changes in the Black Sea marine ecosystem. The Black Sea marine ecosystem manifested significant changes during the last few decades of the 20th century. Healthy ecosystem which was observed in 60 s, early 70s was altered drastically by eutrophication phase in 80 s early 90s. These changes in the Black Sea ecosystem were in particular noted in the phytoplankton biomass, which increased by a few times. (See for example: Oguz et al., 2002) On the basis of the biogeochemical model described above we carried out numerical simulation of the long-term evolution of the Black Sea ecosystem for time period from 1971 until 2001 years. The input parameters for 
Surfoce Phytoplankton (mmolN/m**3), Spring 1971
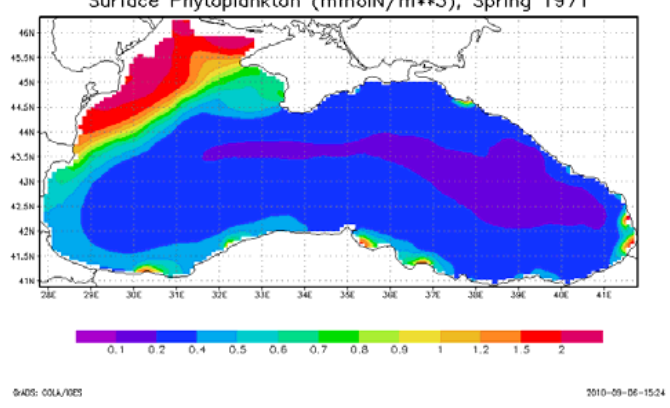

Surface Phytoplankton (mmolN/m**3), Spring 1986

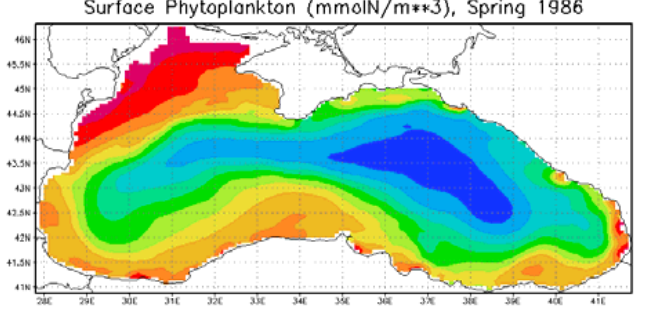

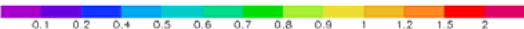

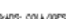

Surfoce Phytoplankton (mmolN/m**3), Spring 1996

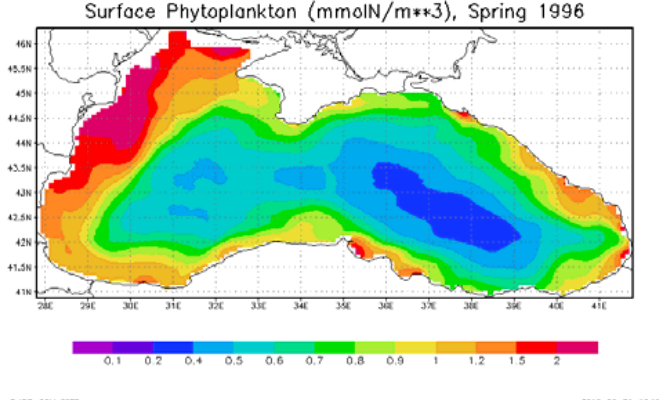

Surface Phytoplankton (mmolN/m**3), Spring 1979
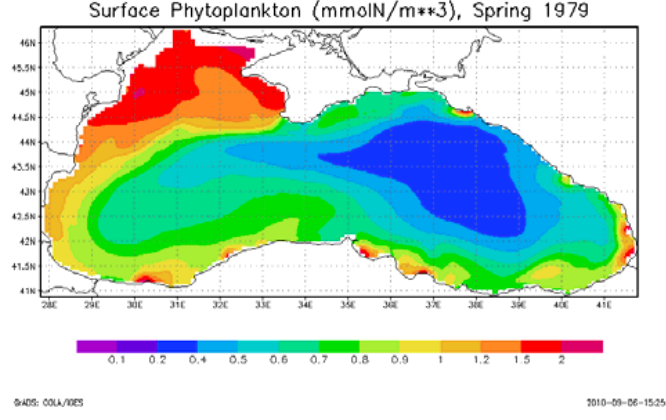

Surface Phytoplankton (mmolN/m*3), Spring 1992

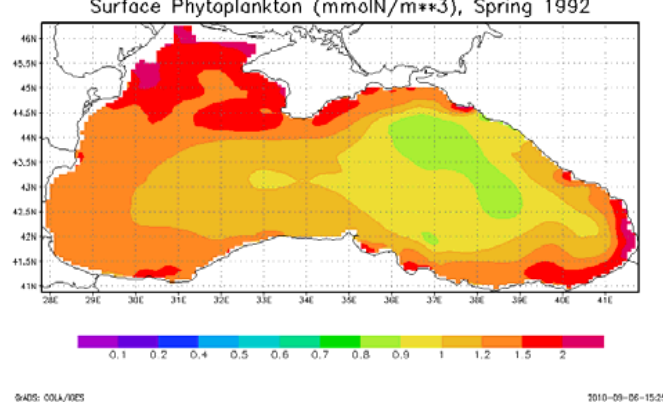

Surface Phytoplankton (mmolN/m**3), Spring 2001

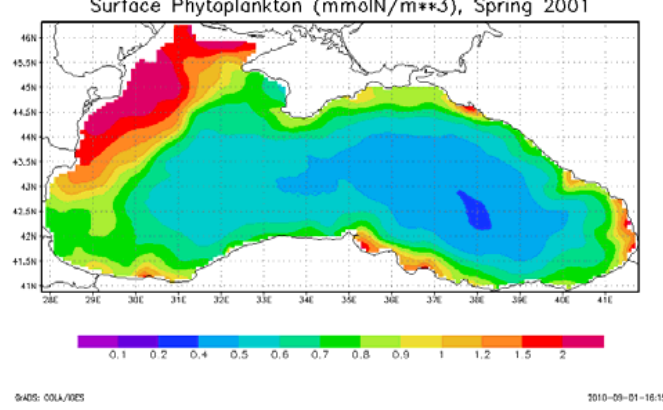

Fig. 21. Spring-mean maps of the surface phytoplankton distribution for different years.

the biogeochemical model were the results obtained with the POM circulation model.

Figure 20 demonstrates evolution of the annual-mean phytoplankton biomass in the upper $50 \mathrm{~m}$ layer for the deep part of the Black Sea basin. The phytoplankton biomass increases approximately twice from value about $1.2 \mathrm{gC} \mathrm{m}^{-2}$ in early seventies to $2 \mathrm{gC} \mathrm{m}^{-2}$ in mid nineties and then it decreases. These changes in the phytoplankton biomass can also be seen in evolution of the surface concentration. The phytoplankton community exhibits a major bloom during the late winterearly spring season, following the period of active nutrient accumulation in the surface waters at the end of the winter mixing season and as soon as the water column receives sufficient solar radiation. The intensity of the spring bloom altered drastically during the time period we consider. This is illustrated on the Fig. 21 showing spring-mean maps of the surface phytoplankton concentrations. The greatest values are observed in early $90 \mathrm{~s}$ - period of intense eutrophication in the Black Sea. This growth of the phytoplankton community until mid of 90 s is due to increase of nutrient volume in the upper layer of the Black Sea.

Changes in marine biology of the Black Sea during these three decades were accompanied by modification of the vertical geochemical structure. The most pronounced signature of the geochemical changes is an increase of nitrate concentration in the oxic/suboxic interface zone from 2 to $3 \mathrm{mmol} \mathrm{m}^{-3}$ in the late 1960 s to $6-9 \mathrm{mmol} \mathrm{m}^{-3}$ during the 1980 s and early $90 \mathrm{~s}$, and then decrease to the value of about $4 \mathrm{mmol} \mathrm{m}^{-3}$ in late 90 s - early 2000s. Figure 22 presents nitrate profiles, derived from modelling, for the point placed approximately in 

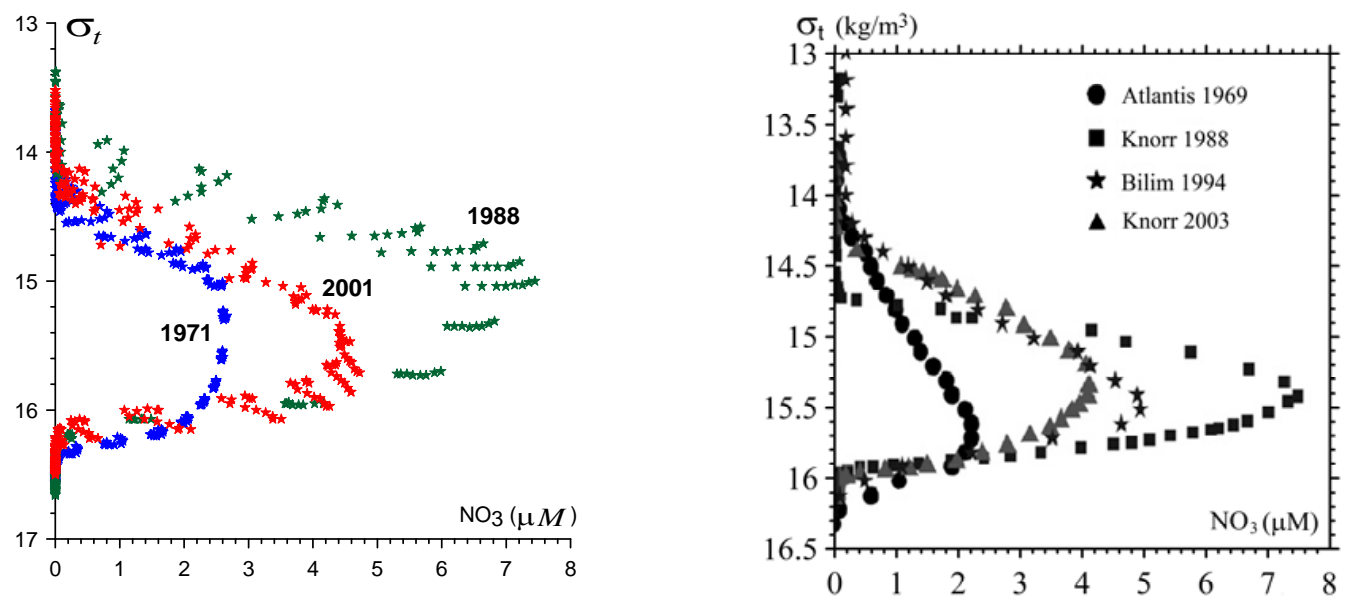

Fig. 22. Derived from modeling nitrate profiles (in $\mu \mathrm{M}$ ) versus sigma-t (in $\mathrm{kg} \mathrm{m}^{-3}$ ) for the central western gyre (left) and nitrate profiles measured by cruise vessels (Oguz and Gilbert, 2007).

the central western gyre for three different years which correspond early, intense and post-eutrophication phases of the Black Sea ecosystem. The values of the nitrate maximum are in good correspondence with the measurements obtained on cruise vessels

The model was also calibrated on chlorophyll-a climatological fields based on the MODIS data (http://oceancolor. gsfs.nasa.gov). The model was run with input parameters corresponded to 2007 year obtained with the MHI circulation model. Numerical simulations of the Black Sea ecosystem with $5 \mathrm{~km}$ grid step demonstrate its ability reproducing large scale spatial features and reaction on the mesoscale dynamics. Figure 23 demonstrates maps of the surface chlorophylla computed by the model (left panel) and MODIS climate, which correspond to winter, spring, summer and autumn.

Satellite color scanner measurements were used to compare the results of the modeling with satellite data. Figure 24 demonstrates temporal variability of the basin averaged surface chlorophyll for the deep part of the basin derived from modeling (blue line) and SeaWiFS data (red line) during 2007 year. Satellite data are two week composited maps of the surface chlorophyll-a concentration, prepared for the Black Sea region (http://blackseacolor.com). The most evident deviation between satellite data and the results of the modeling can be observed in the winter seasons. Green line corresponds to RMS deviation of the model data from SeaWiFS data.

\section{Architecture of the nowcasting and forecasting system}

A pilot version of the Black Sea nowcasting/forecasting system (Korotaev et al., 2006) was built in the framework of FP5 ARENA project. It operated during five days in July 2005 in the manual mode. The system architecture was improved significantly during the next years to avoid manual operation. During ECOOP project phase it operated in real time mode. It forms version V0 of the model currently used in the My Ocean Black Sea Marine Forecasting Centre.

The software controlling the system is presented by three groups. The group of input and pre-processing consists of three sub-groups: ALTIMETRY, NOAASST and METEO. The sub-group ALTIMETRY includes downloading of SLA of missions Topex/Poseidon, ERS-2, Jason-1, Envisat and GFO from the web of AVISO centre and its pre-processing according to the algorithm described in (Korotaev et al., 2001). The sub-group NOAASST is assigned to the preprocessing of IR/AVHRR data received by the HRPT station at MHI to retrieve the SST. The sub-group METEO includes downloading of meteorological analysis and forecast of the sea surface wind, heat fluxes and precipitation/evaporation from the web of NMA (Romania) and their repacking. The group MHI-casting consists of the collection of software for the numerical process control. It provides numerical simulation of the Black Sea circulation, data assimilation in the circulation model and simulation of the surface wave field. The group of the output includes three sub-groups ARCH, GRAF and NET for the data archiving, graphic presentation of the system products and data distribution via Internet.

The scheme of the data flow is presented on Fig. 25. The output of the system is three dimensional temperature, salinity and current velocity fields. Products of the system on the sea surface were regularly presented on the web site http://dvs.net.ua/mp as images and in digital form.

Examples of the system products presented on the web are shown on Fig. 26. 

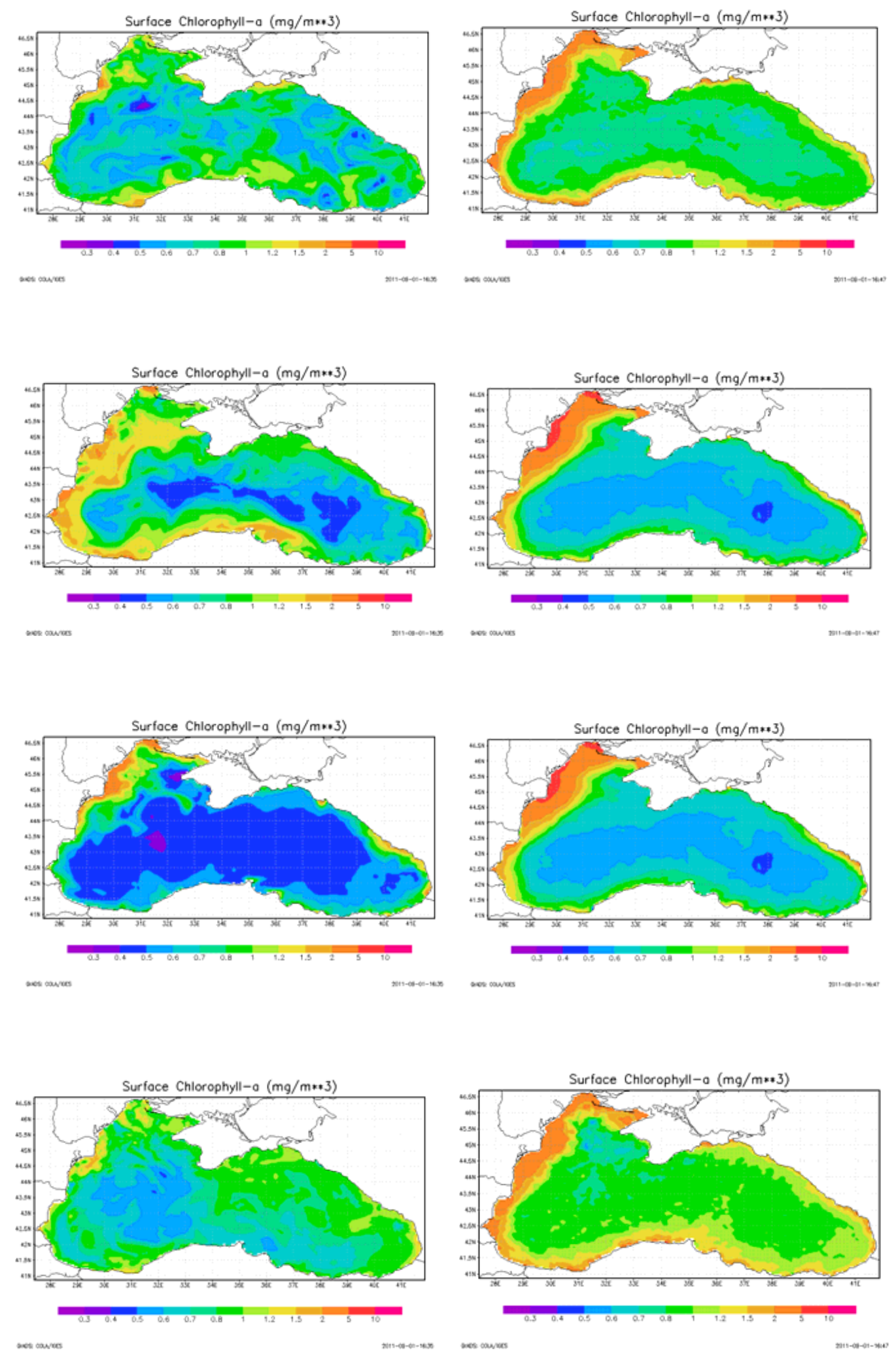

Fig. 23. Maps of the surface chlorophyll-a derived from the model (left panel) and MODIS climate data, which correspond to winter, spring, summer and autumn (from top to bottom). 


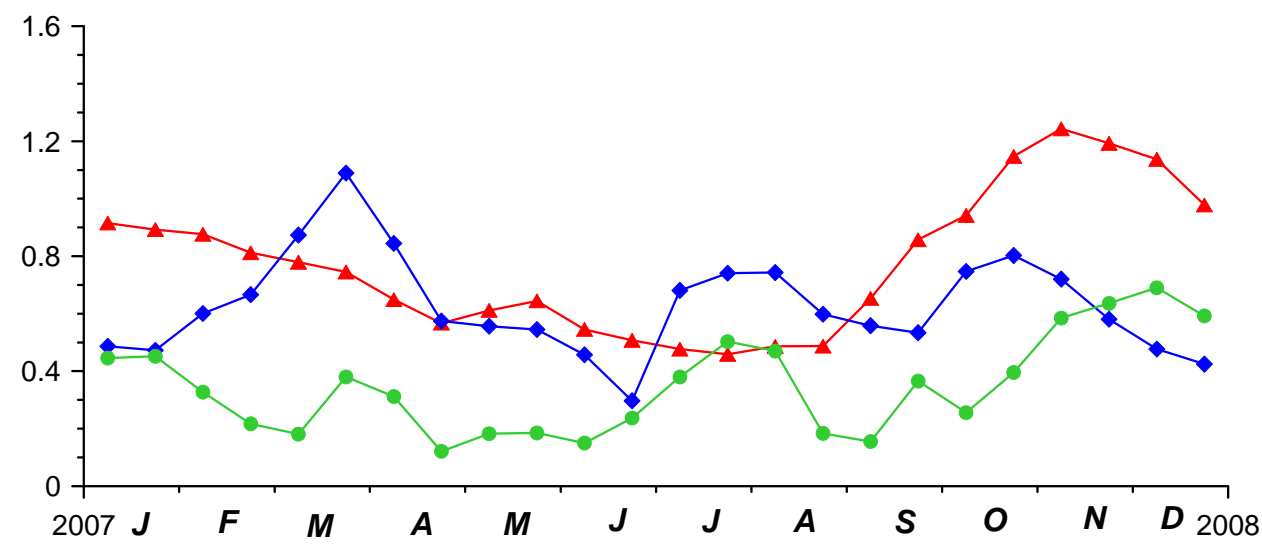

Fig. 24. Temporal evolution of the basin averaged surface chlorophyll-a $\left(\mathrm{mg} \mathrm{m}^{* * 3}\right)$ concentration for the deep part of the basin derived from modeling (blue line), SeaWiFS data (red line) and RMS deviation (green line).

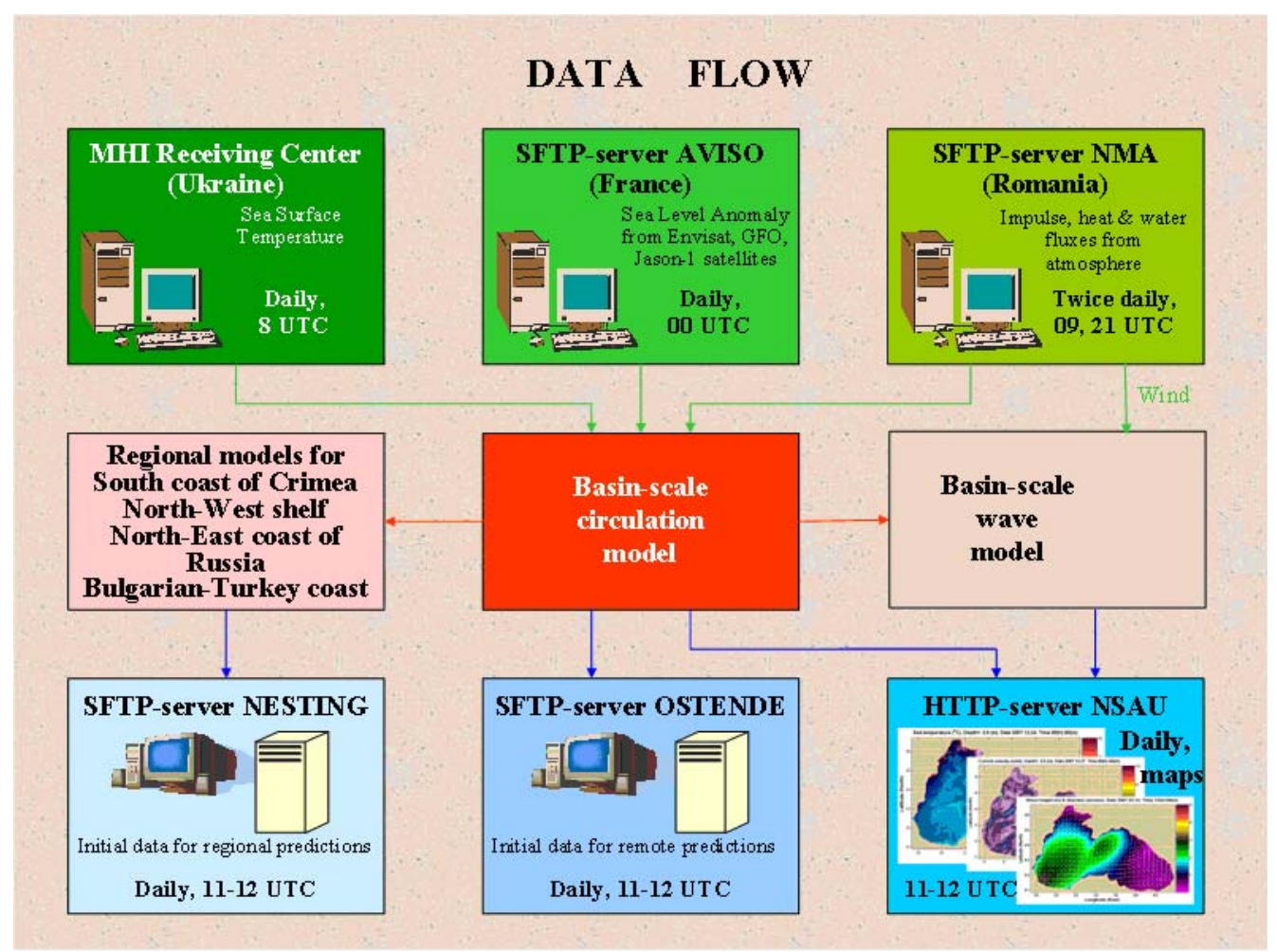

Fig. 25. Data flow in the framework of the Black Sea nowcasting/forecasting system.

\section{Discussion}

The pilot version of the Black Sea nowcasting and forecasting system which was built in the framework of the FP 5 ARENA and FP6 ASCABOS projects was significantly improved later during the FP6 ECOOP project. The basinscale forecasting became operational in the real-time mode from the beginning of the ECOOP project and served as mainframe system for further development of the operational coastal forecasting systems in the Black Sea. Started from "V0 version" it was upgraded to the Black Sea GOOS system "V2". This last version consists of a regional system, covering the entire Black Sea area, and 3 sub-regional systems covering respectively: the North Western shelf, the Bosphorus and Western shelf, and the South coast of Crimea and North East Black sea. The paper was targeted at the description of development of the basin-wide nowcasting and forecasting system. The circulation model, which is the core 

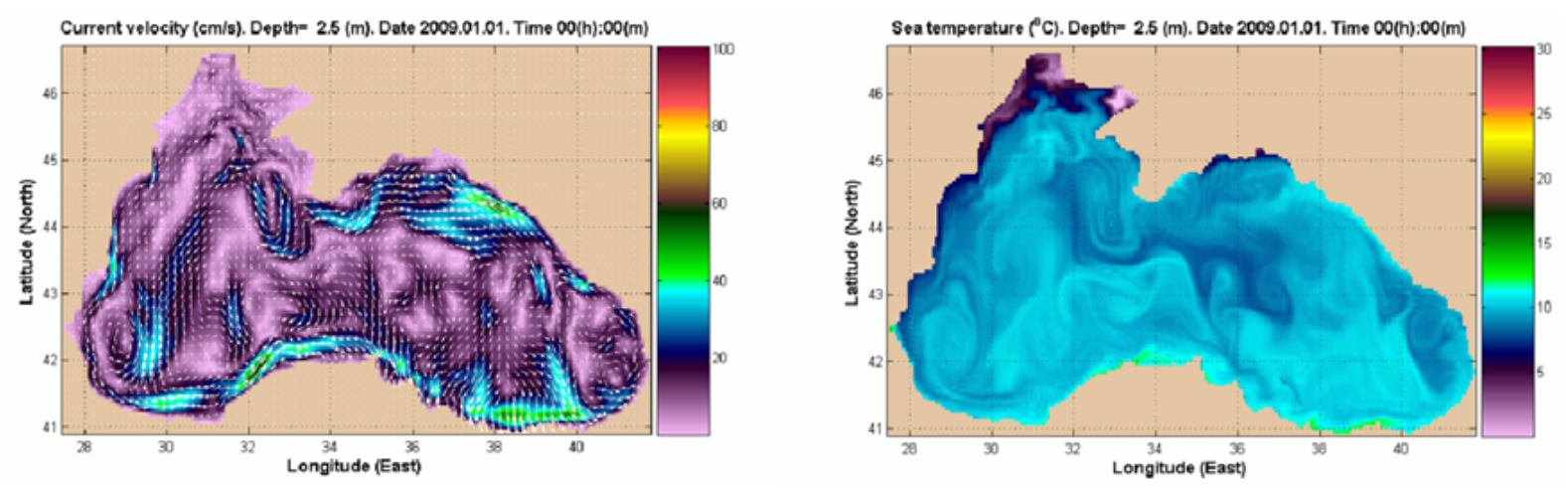

Fig. 26. Examples of the Black Sea nowcasting/forecasting system products: left - surface currents, right - sea surface temperature.

of the system, was improved during the ECOOP by including a new parameterization of the vertical mixing processes. The models have been subject to the qualitative and quantitative tests, which are the essential part of the system. Archive climatic, hydrographical surveys data and measurements from the drifter and profiling floats were used for the models calibrations.

The model reproduces reasonably well upper layer thermodynamics and vertical stratification of temperature and salinity fields, particularly upper mixed layer, cold intermediate layer and permanent pycnocline. Simulated current velocity displays the Rim Current and its seasonal and mesoscale variability. Including quasi-permanent anticyclonic eddies onshore from the stream jet. At the same time there is a broad field of work to improve the model to achieve better quantitative correspondence of the simulated fields with observations. One of possible future improvement of the qualitative skill of the model is connected with further perfection of the upper layer thermodynamics. Our experience shows that current version of the model describes well relatively slow evolution of the upper layer of the sea on seasonal scales however less efficient when sharp atmospheric fronts crossing the basin. We assume that more efficient parameterization of the mixed layer turbulence is requested in such conditions.

The accuracy of the upper layer simulations depends also on the quality of atmospheric forcing provided by meteorological model. Simulations presented in the paper are based on the ALADIN family model runs with $24 \mathrm{~km}$ resolution. Increase of the spatial resolution of the regional atmospheric forecast and careful analysis of available atmospheric forcing for the Black Sea should permit to improve the simulation of the basin thermodynamics.

It was mentioned in the paper that the model demonstrates a slow trend in the permanent pycnocline. More careful tuning of vertical and lateral diffusion should help to reduce that trend. Probably better space resolution of the model allowing explicit resolution of submesoscales permits not only to simulate more realistic currents but also reduce temperature and salinity trends in the permanent pycnocline.

More or less realistic simulations of the Black Sea dynamics are achieved due to assimilation of altimetry, space SST and climatic temperature and salinity profiles. Simple assimilation scheme based on the optimal interpolation is applied. Further improvement of the system efficiency demands application of more sophisticated data assimilation approaches. Optimal interpolation approach raises too high the weight of the assimilated data and generates artificial variability of vertical velocity according to our experience. Simulation of the error statistics as it is requested by the Kalman filter technique even in simplified manner reduces mentioned above problems. Therefore transition to more sophisticated data assimilation algorithm is crucial for the improvement of the system efficiency. It is important also to assimilate available profiling float data to keep close to the reality the permanent pycnocline position and gradients as it was explained earlier.

In addition the Black Sea forecasting system was added with the biogeochemical model. Together with the circulation model it allows describing evolution of the Black Sea ecosystem. Calibration tests showed reasonable qualitative consistency of simulated biogeochemical parameters to the general concept of the Black Sea ecosystem annual and interannual evolution. Obtained results are encouraging but future improvement of the model should be done in a few directions. More careful qualitative calibration of the model should be done when multidisciplinary observations will be available in the basin. Improved model should include additional compartments such as jellyfishes, important chemical elements. Implementation of the real-time space sea colour data assimilation is also important issue of the future system development.

The system architecture was improved significantly to avoid manual operation and during ECOOP project phase it operated in real time mode. The operational system established during ECOOP is the V0 version of the basin-wide nowcating and forecasting system in the frame of the FP7 My Ocean project. 
Acknowledgements. The research leading to the results has received funding from the Eu ropean Community's Sixth Framework Programme under the grant agreement No 036355 (European COastal-shelf sea Operational observing and forecasting system).

Edited by: S. Cailleau

\section{References}

Agoshkov, V. I., Ipatova, V. M., Zalesny, V. B., Parmuzin, E. I., and Shutyaev V. P.: Problems of variational assimilation of observational data into Ocean general circulation models and methods for their solution, Izvestiya, Atmos. Ocean. Phys., 46, 677-712, 2010.

Arakawa, A.: Computational design for long-term numerical integration of the equations of fluid motion: Two-dimensional incompressible flow. Part I, J. Comput. Phys., 1, 119-43, 1966.

Blatov, A. S., Bulgakov, N. P., Ivanov, A. N., Kosarev, A. N., and Tujilkin, V.: Variability of the hydrodynamical fields in the Black Sea, 240 pp., Gidrometeoizdat, St. Petersburg, 1984 (in Russion).

Demyshev, S. G. and Korotaev, G. K.: Numerical energy-balanced model of baroclinic currents in the ocean with bottom topography on the C-grid, in: Numerical models and results of intercalibration simulations in the Atlantic ocean, Moscow, 163-231, 1992 (in Russian).

Demyshev, S. G., Dovgaya, S. V., and Markova, N. V.: Numerical simulations of hydrophysical fields of the Black Sea from January to September 2006, Ecological Security of Coastal and Shelf Zone and Complex use of Shelf Resources, 19, 355-369, 2009 (in Russian).

Demyshev, S., Knysh, V., Korotaev, G., Kubryakov, A., and Mizyuk, A.: The MyOcean Black Sea from a scientific point of view, Mercator Ocean Newsletter, 39, October, 16-24, available at: http://www.mercator-ocean.fr/documents/lettre/lettre_39_en. pdf, 2010.

Dorofeyev, V. L., Demyshev, S. G., and Korotaev, G. K.: Eddyresolving model of the Black Sea circulation, Ecological Security of Coastal and Shelf Zone and Complex use of Shelf Resources, 71-82, 2001 (in Russian).

Dorofeyev, V. L. and Korotaev, G. K.: Assimilation of the satellite altimetry data in the eddy-resolving model of the Black Sea circulation, Marine Hydrophys. J., 1, 52-68, 2004a (in Russian).

Dorofeyev, V. L. and Korotaev, G. K.: Validation of the results of modeling the Black Sea circulation based on the data of floating buoys, Ecological Security of Coastal and Shelf Zone and Complex use of Shelf Resources, 11, 63-74, 2004b (in Russian).

Friedrich, H. J. and Stànev, E. V.: Parameterization of vertical diffusionin numerical model of the Black Sea, Small sea turbulence and mixing in the ocean, Elsevier Oceanography Series, 46, 151167, 1988.

Ghill, M. and Malanotte-Rizzoli, P.: Data assimilation in meteorology and oceanography, Adv. Geophys., B. Saltzmann, ed., Academic Press, 33, 141-266, 1991.

Knysh, V. V., Saenko, O. A., and Sarkisyan, A. S.: Method of assimilation of altimeter data and its test in the tropical North Atlantic, Rus. J. Numer. Anal. Math. Modelling, 11, 5, 333-409, 1996.

Knysh, V. V., Kubryakov, A. I., Inyushina, N. V., and Korotaev, G. K.: Reconstruction of the climatic seasonal Black Sea circulation by means of sigma-coordinate model and assimilation of the temperature and salinity data, Ecological safety of coastal and shelf zone and complex use of their resources, Sevastopol, 12, 243-265, 2005 (in Russian).

Konovalov, S. K. and Eremeev, V. N.: Monitoring of the Black Sea Biogeochemical Properties: Major Fiatures and Changes, in press, 2011.

Korotaev, G. K., Saenko, O. A., and Koblinsky, C. J.: Satellite altimetry observations of the Black Sea level, J. Geoph. Res., 106, C1, 917-933, 2001.

Korotaev, G. K., Oguz, T., Nikiforov, A. A., and Koblinsky, C. J.: Seasonal, interannual and mesoscale variability of the Black Sea upper layer circulation derived from altimeter data, J. Geoph. Res., 108, 3122, doi:10.1029/2002JC001508, 2003.

Korotaev, G. K., Dorofeyev, V. L., and Smirnova, T. Yu.: Accuracy of the diagnosis of surface currents in the system of the Black Sea satellite monitoring, Ecological Security of Coastal and Shelf Zone and Complex use of Shelf Resources, 11, 75-92, 2004 (in Russian).

Korotaev, G. K., Cordoneanu, E., Dorofeyev, V. L, Fomin, V., Grigoriev, A. V., Kordzadze, A., Kubryakov, A. I., and Oguz, T.: Near-operational Black Sea nowcasting/forecasting system, in: European Operational Oceanography: Present and Future, 4th EuroGOOS Conference, 6-9 June 2005, Brest, France, 2006.

Korotaev, G. K., Huot, E., Le Dimet, F.-X., Herlin, I., Stanichny, S. V., Solovyev, D. M., and Wu, L.: Retrieving ocean surface current by 4-D variational assimilation of sea surface temperature images, Remote Sens. Environ., 112, 4, 1464-1475, 2008.

Mellor, G. L., and Yamada, T.: Development of a turbulence closure model for geophysical fluid problems, Rev. Geophys. Space Phys., 20, 851-875, 1982.

Obukhov, A. M.: Turbulence in temperature heterogeneous atmosphere, Proceedings of Institution of Theoretical Physics SU Academy of Science, 24, 3-42, 1946.

Oguz, T., Latun, V. S., Latif, M. A., Vladimirov, V. V., Sur, H. I., Makarov, A. A., Ozsoy, E., Kotovshchikov, B. B., Eremeev, V., and Unluata, U.: Circulation in the surface and intermediate layers of the Black Sea, Deep Sea Res. Pt. I, 40, 1597-1612, 1993.

Oguz, T., Ducklow, H. W., Malanotte-Rizzoli, P., Murray, J. W., Shushkina, E. A., Vedernikov, V. I., and Unluata, U.: A physicalbiochemical model of plankton productivity and nitrogen cycling in the Black Sea, Deep-Sea Res., Pt. I, 46, 4, 597-636, 1999.

Oguz, T., Ducklow, H. W., and Malanotte-Rizzoli, P.: Modeling distinct vertical biochemical structure of the Black Sea: Dynamical coupling of the oxic, suboxic, and anoxic layers, Global Biochem. Cy., 14, 4, 1331-1352, 2000.

Oguz, T., Ducklow, H. W., Purcell, J. E., and Malanotte-Rizzoli, P.: Modeling the response of top-down control exerted by gelatinous carnivores on the Black Sea pelagic food web, J. Geophys. Res, 106, C3, 4543-4564, 2001.

Oguz, T., Malanotte-Rizzoli, P., Ducklow, H. W., and Murray J. W.: Interdisciplinary Studies Integrating the Black Sea Biogeochemistry and Circulation Dynamics, Oceanography, 15(3), 4$11,2002$.

Oguz, T. and Gilbert, D.: Abrupt transitions of the top-down controlled Black Sea pelagic ecosystem during 1960-2000: evidence for regime shifts under strong fishery exploitation and nutrient enrichment modulated by climate-induced variations. Deep-Sea Res Pt. I, 54, 220-242, 2007. 
Pacanovsky, R. C. and Philander, G.: Parameterization of vertical mixing in numerical models of the tropical ocean, J. Phys. Oceanogr., 11, 1442-1451, 1981.

Ratner, Yu.B. and Bayankina, T. M.: Comparison of the surface temperature values obtained from the model of the Black Sea dynamics and the data of SVP-drifters in March-August 2003, Ecological Security of Coastal and Shelf Zone and Complex use of Shelf Resources, 11, 51-62, 2004 (in Russian).

Sur, H. I., Ozsoy, E., and Unluata, U.: Boundary current instabilities, upwelling, shelf mixing and eutrophication processes in the Black Sea, Progr. Oceanogr., 33, 249-302, 1994.
Vedernikov, V. I. and Demidov, A. B.: Vertical distributions of primary production and chlorophyll during different seasons in deep part of the Black Sea, Oceanology, Engl. Transl., 37, 376-384, 1997.

Zalesny, V., Tamsalu, R., and Mannik, A.: Multidisciplinary numerical model of a coastal water ecosystem, Russ. J. Numer. Anal. Math. Modelling, 23, 2, 207-222, 2008.

Zalesny, V. B. and Tamsalu, R.: High-resolution modeling of a marine ecosystem using the FRESCO hydroecological model. Izvestiya, Atmos. Ocean. Phys., 45, 108-122, 2009. 